\title{
Modelling Approaches for Inelastic Behaviour of RC Walls: Multi-level Assessment and Dependability of Results
}

\author{
João Pacheco Almeida • Danilo Tarquini • \\ Katrin Beyer
}

Received: 5 September 2014 / Accepted: 16 September 2014

(C) CIMNE, Barcelona, Spain 2014

\begin{abstract}
The severe damage and collapse of many reinforced concrete (RC) wall buildings in the recent earthquakes of Chile (2010) and New Zealand (2011) have shown that $\mathrm{RC}$ walls did not perform as well as required by the modern codes of both countries. It seems therefore appropriate to intensify research efforts towards more accurate simulations of damage indicators, in particular local engineering demand parameters such as material strains, which are central to the application of performance-based earthquake engineering. Potential modelling improvements will necessarily build on a thorough assessment of the limitations of current state-ofthe-practice simulation approaches for RC wall buildings. This work compares different response parameters obtained from monotonic analyses of RC walls using numerical tools that are commonly employed by researchers and specialized practitioners, namely: plastic hinge analyses, distributed plasticity models, and shell element models. It is shown that a multi-level assessment-wherein both the global and local levels of the response are jointly addressed during pre- and
\end{abstract}

J. P. Almeida $(\varangle)$

Earthquake Engineering and Structural Dynamics Laboratory (EESD), School of Architecture, Civil and Environmental Engineering (ENAC), École Polytechnique Fédérale de Lausanne (EPFL), EPFL ENAC IIC EESD, GC B2 484, Station 18, 1015 Lausanne, Switzerland e-mail: joao.almeida@epfl.ch

D. Tarquini

Earthquake Engineering and Structural Dynamics Laboratory (EESD), School of Architecture, Civil and Environmental Engineering (ENAC), École Polytechnique Fédérale de Lausanne (EPFL), EPFL ENAC IIC EESD, GC B2 514, Station 18, 1015 Lausanne, Switzerland

e-mail: danilo.tarquini@epfl.ch

\section{K. Beyer}

Earthquake Engineering and Structural Dynamics Laboratory (EESD), School of Architecture, Civil and Environmental Engineering (ENAC), École Polytechnique Fédérale de Lausanne (EPFL), EPFL ENAC IIC EESD, GC B2 504, Station 18, 1015 Lausanne, Switzerland e-mail: katrin.beyer@epfl.ch post-peak response-is fundamental to define the dependability of the results. The displacement demand up to which the wall response can be predicted is defined as the first occurrence between the attainment of material strain limits and numerical issues such as localization. The present work also presents evidence to discourage the application of performance-based assessment of RC walls relying on nonregularized strain EDPs.

\section{Introduction}

The idea that a structure should be able to resist minor seismic shaking without damage, withstand a moderate earthquake possibly experiencing some non-structural damage, and survive a major event without collapse, was born in the late 1950s [1]. Such statement embodies the concept of performance-based earthquake engineering (PBEE), which builds on the definition of desired performance targets [2]. Until the early 1970s, these targets were quantified by empirical criteria, e.g. for use in equations estimating the base shear [3]. As research progressed, such empirical relations were replaced by equations founded upon physical principles, and uncertainties were also progressively considered [4]. At the beginning of the twenty-first century, PBEE found its way in assessment [5-11] and design codes [1214]. All these guidelines share a common feature: for each desired performance objective, they prescribe discrete, performance levels - ranging from fully operational to collapse prevention - and discrete hazard levels.

Characterising these performance levels requires the definition of a set of engineering demand parameters (EDPs) on which performance assessment can be based. The values of this set of EDPs need to be estimated from numerical simulations. It should be noted that within a formal theo- 
retical setting of performance-based assessment, a distinction exists between EDPs and damage measures: Damage measures describe the damage and its consequences to structural or non-structural components while EDPs include all engineering parameters based on which such damage can be estimated. In reinforced concrete (RC) structures, examples of damage measures are maximum crack width, spalling of cover concrete, buckling or fracture of longitudinal steel, crushing of core concrete, while EDPs are, for example, member forces, inter-storey drift values or maximum tensile and compressive strains. Floor accelerations and velocities, residual displacements, displacement ductility, and cumulative measures like hysteretic energy dissipation, are further examples of EDPs that can be suitable to describe the building performance.

Until the 1990s, traditional EDPs were limited to member forces and inter-storey drifts, obtained from equivalent lateral force and/or response-spectrum analysis. These analysis methods are still the basis of many current design codes. From the early to mid-1990s, the development of nonlinear methods of analysis led to the introduction of deformationbased EDPs, such as member chord rotations [15] and interstory drifts [16]. Many commercial software packages of structural analysis now include relatively advanced nonlinear modelling and analysis features, which are used by practitioners to estimate the aforementioned EDPs (e.g. Computers and Structures Inc. [17,18]) and a number of research analysis softwares have been specifically developed for seismic analysis purposes [19-21].

EDPs such as member forces and inter-storey displacements are 'global-level' parameters, i.e., quantities that refer to the member or structural level. However, the advancement of numerical simulation tools and new code and guidelines specifications are progressively promoting the supplementary use of local EDPs, e.g. quantities that refer to the material or sectional levels, which are considered to better and more directly correlate to damage [22]. They include, amongst others, rebar strains, cover and core concrete strains, maximum curvature, and curvature ductility [23]. For instance, the reinforcing steel tensile strain can be defined as the EDP to assess the maximum residual crack width, which can in turn be compared to a reference value to assess if the damage level is negligible or requires a certain repair method. Other examples are the cover and core concrete compressive strains, which can be related to a minor spalling of the cover (slight damage level) or a major spalling exposing the longitudinal reinforcement (moderate damage level).

PBEE demands therefore an accurate estimation of both global and local EDPs, which can be estimated from numerical analyses of different degrees of sophistication. This paper addresses the suitability of different numerical models for the seismic analysis of RC walls. These structural members are frequently used to brace mid- to high-rise buildings against earthquakes. They are often preferred to frames since they tend to lead to smaller inter-storey drifts and therefore smaller non-structural damage. However, the recent earthquakes of Chile (2010) and New Zealand (2011) have shown that RC walls did not perform as well as expected [24]. This observation calls for an assessment of the capabilities of different numerical tools to estimate global and local EDPs of walls. Unlike for frames, shear deformations in RC walls contribute typically in a significant manner to the total deformations even if the walls are designed to develop a flexural mechanism. Since the shear deformations influence the axial strain distribution in the wall section, the RC walls should be ideally modelled using solid, shell or membrane elements if vertical strain measures are used as EDPs. However, due to the large computational costs associated to these models and the expertise required for their setup, $\mathrm{RC}$ walls are often analysed using beam element models or even simpler plastic hinge models.

Starting from the following section, existing modelling approaches are divided into three main categories: plastic hinge analyses (PHAs), distributed plasticity models (DPMs), and shell element models (SEMs). The selection was based on a two-fold criterion. On the one hand, it was intended to use simulation methods of distinct levels of complexity, roughly spanning the existing modelling spectrum. On the other hand, only the approaches and software that are commonly used and available to researchers and specialized engineers were considered. Theoretical and numerical features of plastic hinge analysis and distributed plasticity models will be analysed in more detail in the following sections.

Nonlinear shell element models are powerful simulation techniques that take into account directly the interaction between axial force, flexure and shear [25]. Modelling the behaviour of RC members subjected to torsion with beam elements is a very challenging issue [26], and in such case the use of shell elements is again shown to be a suitable option. Although initially limited to research purposes [27], the increase of computational power is progressively bringing this modelling approach closer to being a practical tool for design engineers, delivering reliable and robust results [28]. Since shell elements, associated to multiaxial constitutive laws, are amongst the available tools of analysis that provide more detailed results, they have been used to improve or calibrate modelling techniques demanding less computational power [29].

It should be noted that there are other wall modelling strategies that do not fit clearly into any of the three previously mentioned categories. These hybrid methods traditionally borrow some features from each approach and in general offer significant additional flexibility in terms of definition of input parameters. Among these hybrid methods the so-called 'multiple-vertical-line element' and ensu- 
ing developments [30], as well as the 'wide-column models', composed of an assembly of vertical beam-column elements and horizontal links to represent the wall segments $[31,32]$, are often applied when modelling RC wall buildings. Three-dimensional lattice models have also been used for the simulation of the experimental torsional and biaxial cyclic response of RC structural members [33]. This strategy has been further developed by $\mathrm{Yu}$ and Panagiotou [34,35], who apply a 3D beam-truss model for nonplanar RC walls which also accounts for mesh-size effects. They use nonlinear beam and truss elements in the vertical and horizontal directions, nonlinear truss elements in the diagonals to represent the diagonal field of concrete, and linear elastic beams to simulate the out-of-plane stiffness.

Exploring the complex range of available modelling approaches has naturally raised interest within the scientific community $[29,36,37]$. However, most of the comparisons typically focus on the global level of analysis and do not address comprehensively the relation between the latter and the local levels of the mathematical model in consideration. The present paper compares some of the most common modelling approaches for the simulation of the inelastic behaviour of RC walls based on a joint assessment of both global and local EDPs, as explained in Sect. 2. The modelling approaches are compared in particular regarding the relationships between the different levels of analysis (i.e., at which top displacement a specific strain limit is attained), numerical problems, convergence issues, and the validity range of the results. The latter is defined in Sect. 3. The manuscript also assesses the influence of constitutive models and the finite element formulation on the relationship between global and local EDPs. The consideration of shear modelling in the different approaches and confinement effects are shortly addressed in Sects. 4 and 5, respectively.

In order to ease the interpretation of the results, a single RC wall is subjected to a simple pushover analysis (Sect. 6), hence avoiding the number of additional complexities brought about by the use of nonlinear dynamic time histories or multi-member structural systems. Different shear span ratios are considered for the structural member, which is intended to evaluate the influence of shear deformations. Within the scope of the present work, it is noted that only the SEMs accurately account for shear deformations. These models will be used as benchmark to assess the extent to which pure flexural models, such as beam elements based on the Euler-Bernoulli hypothesis, can capture responses that have non-negligible shear deformations. Confinement models and other physical phenomena can also impact significantly the results and are thus separately addressed in a separate section of the manuscript.

It should be underlined that the purpose of this study is not to validate the results of different modelling approaches against experimental results, but rather to evaluate and inter- pret the scatter of the response provided by distinct state-ofthe-practice simulation methods that build on the same (or asclose-as-possible) input parameters, constitutive relations, confinement models, etc. Still, for each simulation technique there is a large number of non-obvious modelling choices (mesh discretization, certain parameters in the material models, confinement definition, etc) that affect the outcome of the inelastic analyses. Furthermore, there is also typically a significant level of uncertainty associated to material properties or reinforcement details of the RC specimen. The two facts above combined make it generally possible to justify a combination of these modelling choices that show a versatile, at times surprising, ability to match selected experimental results. In order to avoid such temptation, the decision of not including comparisons against experimental results was deliberately taken upfront.

\section{Multi-level Analyses in State-of-Practice Modelling Approaches}

The present section recalls the underlying assumptions and the distinct levels of analysis that are associated to each of the mathematical models used in this study, pointing out how they relate and compare. An effort was made to summarise the most classical features of traditional PHAs, DPMs, and SEMs in Table 1, wherein the up arrows, down arrows, and bullet points stand for relative advantages, disadvantages, and general comments respectively. The distributed plasticity models are further subdivided into displacement-based (DB) and force-based (FB) approaches, since these two beam-column approaches correspond to fundamentally distinct finite element formulations that yield different results and hence require specific interpretations (Table 2). A solid understanding of the information in the tables below, which should be self-explanatory, enables more insightful interpretations of the numerical results and critical comparisons between the approaches. A few pertinent notes follow.

The first remark relates to the classical plastic hinge analysis (PHA). It was developed for hand calculations in the midtwentieth century. A computational counterpart appeared later on: it is the category of beam-column finite elements that are commonly referred to as lumped (or concentrated) plasticity models (LPMs), wherein a flexural hinge representing the inelastic behaviour is assigned to each extremity of the element. To underline their common root, the 'plastic hinge analysis' and 'lumped plasticity models' are described together in the first row of Table 1 but the points in which they differ are explicitly indicated by referring to the acronyms 'PHA' and 'LPMs'.

Secondly, it is highlighted that there is a multitude of modelling approaches spanning between the categories pointed out in the tables below. Although it is not possible to 


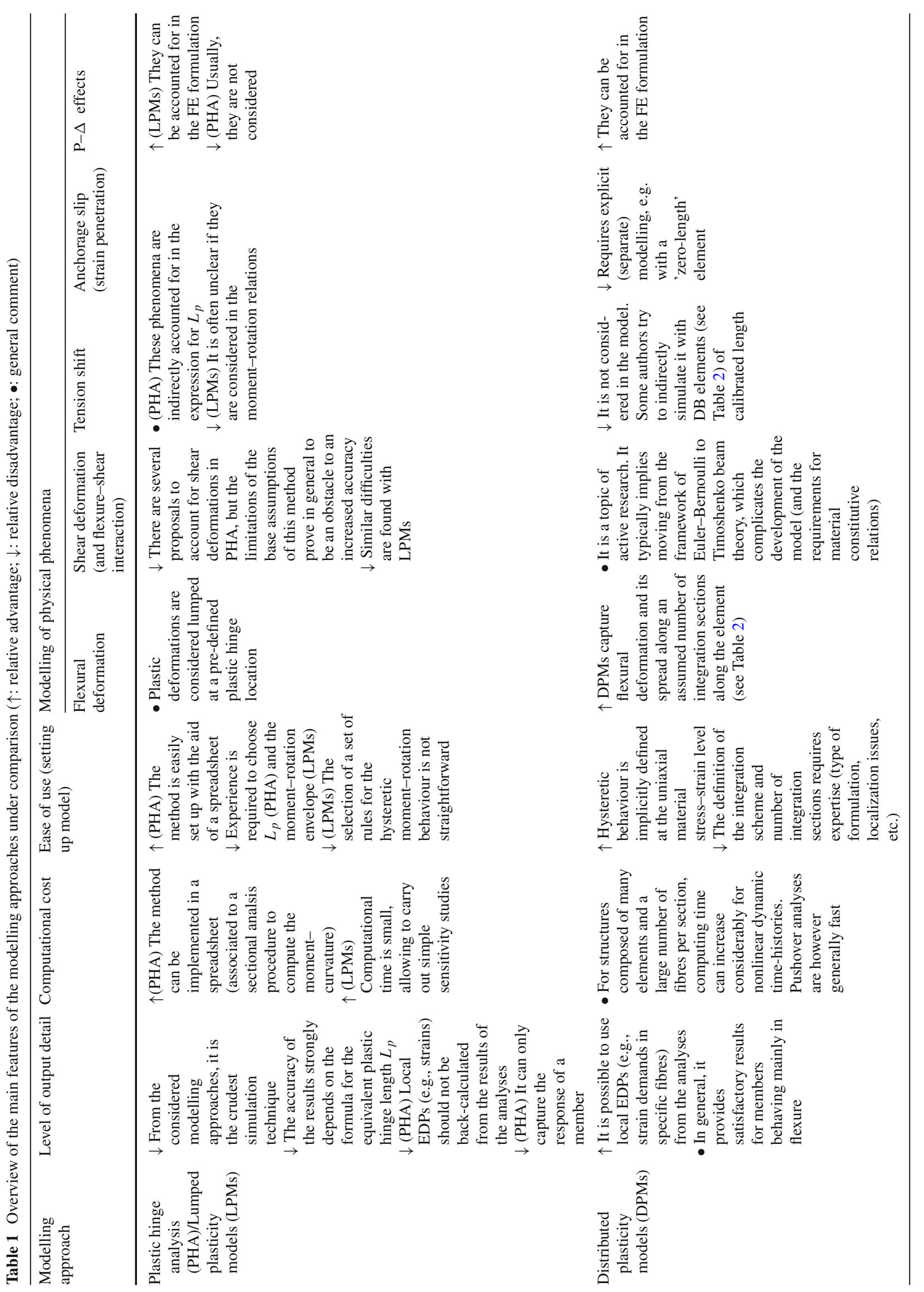




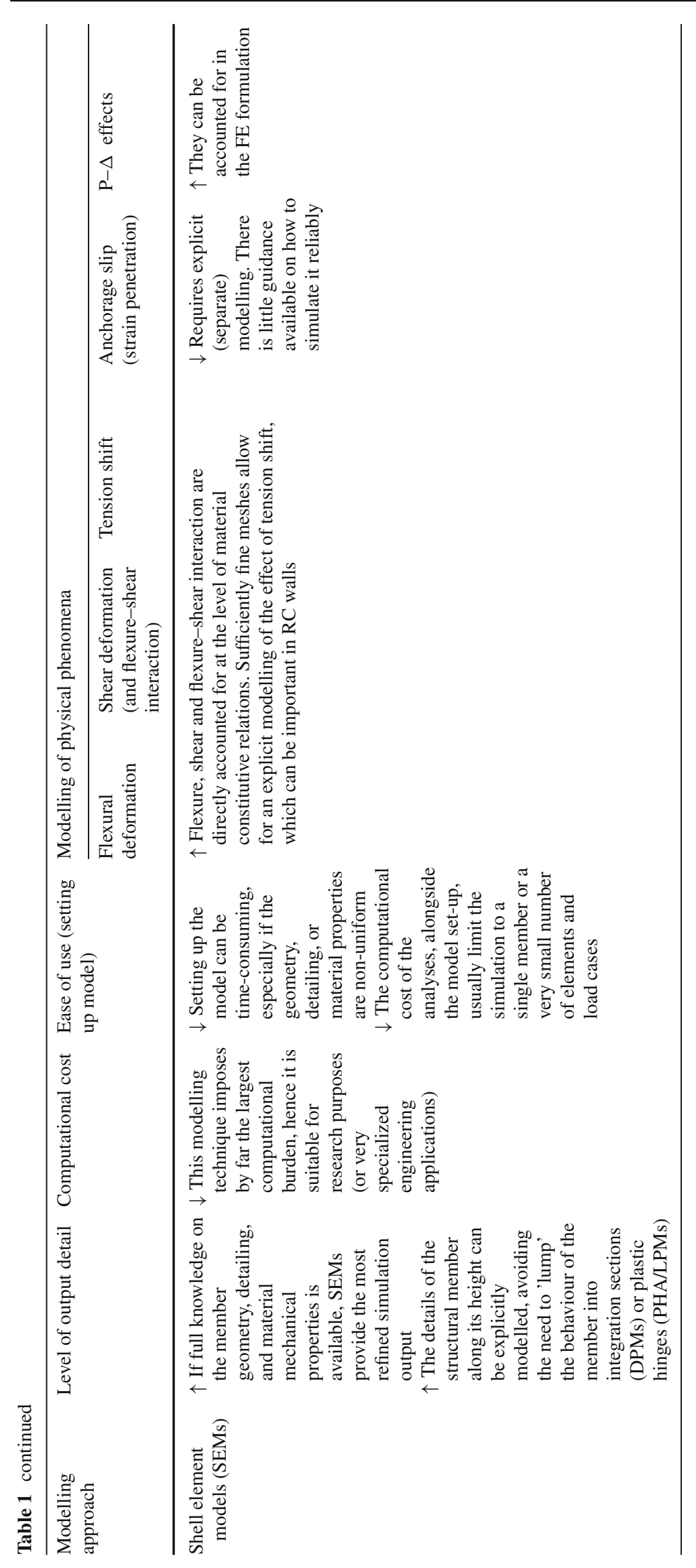




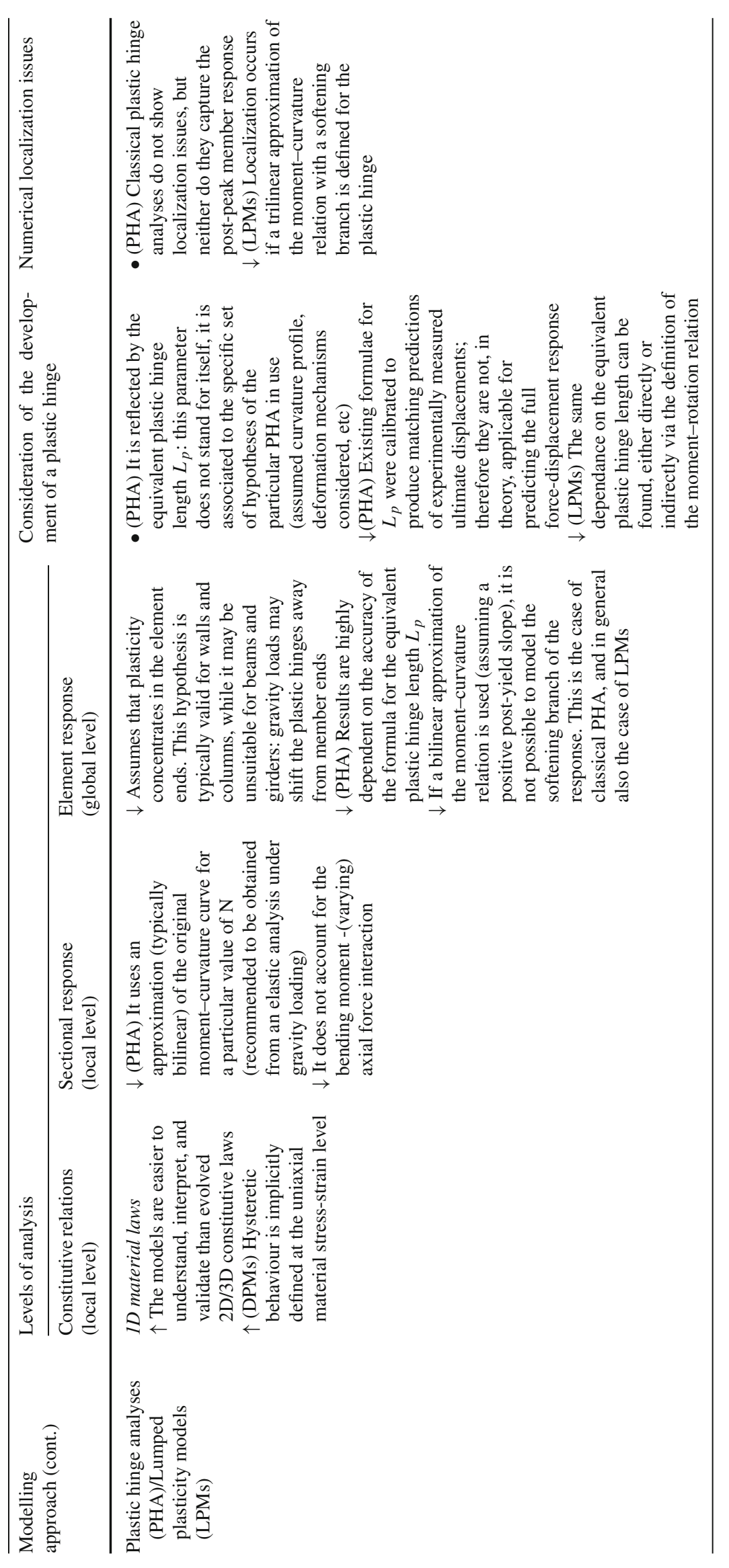




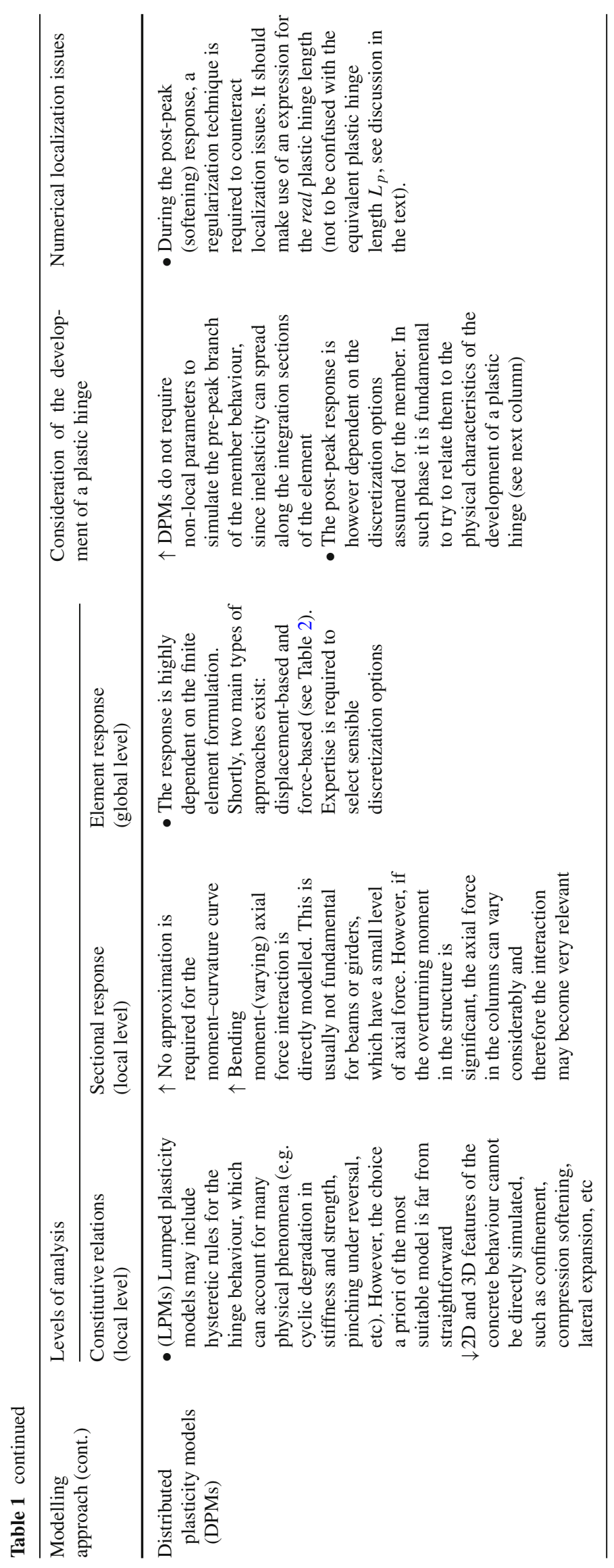




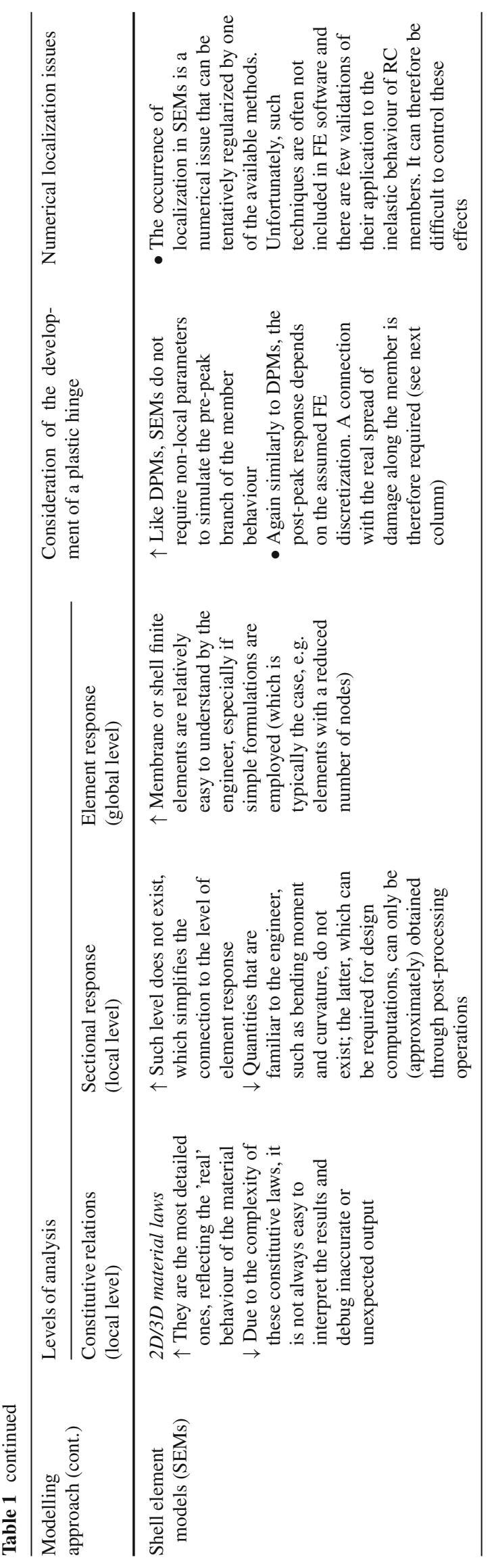


Table 2 Simplified comparative overview on displacement-based versus force-based formulations ( $\uparrow:$ relative advantage; $\downarrow$ : relative disadvantage; -: general comment)

\begin{tabular}{ll}
\hline $\begin{array}{l}\text { Distributed plasticity } \\
\text { models }\end{array}$ & Displacement-based formulation (DB)
\end{tabular}

Hypotheses $\quad$ Assumed displacement field along the element: cubic Hermitian polynomials for the transverse displacement field and linear Lagrangian interpolation functions for the axial displacement $\Rightarrow$ Linear curvature and constant axial strain (at the reference axis) along the element

Finite element implementation

$\uparrow$ Straightforward state determination algorithm, corresponding to classical finite element implementation (no iterative routines are involved)

Level of output detail

Applications

Localization

\begin{abstract}
$\downarrow$ DB elements only provide the exact solution for the problem of an element with linear elastic material subjected to nodal forces. Linear curvature and constant axial strain at the reference axis along the element are unsatisfactory for nonlinear analysis and/or members subjected to span loads

$\downarrow$ Equilibrium is only verified in average, which leads to a number of critical issues: unrealistic variations of axial force between different integration sections of the element, inaccurate sectional response, etc.

$\downarrow$ 'Artificial' consideration of span loads
\end{abstract}

Applications

$\uparrow$ DB elements are still widely used because: (i) many FE software are still based on this approach, (ii) curvature and strain demands in the sections are generally smaller than with exact FB elements, which is sometimes convenient, (iii) some authors use it to indirectly simulate other physical phenomena such as tension shift

- It provides a stiffer and stronger prediction of the objective ('exact') response

$\downarrow$ Meshing of the member into several elements is required to capture the nonlinear structural response or the behaviour of members subjected to span loads

- Localization can occur in all the integration sections of the element

In such a case, the length of the most strained member corresponds to the real plastic hinge length, which can be used as a regularization criterion
- The force field is obtained through an exact solution of the differential equations of equilibrium. E.g., for nodal loading it corresponds to a linear Lagrangian shape function for the bending moment and a constant approximating polynomial for the axial force along the element

$\downarrow$ The inter-element continuity of displacements is more difficult to enforce, requiring an iterative solution algorithm based on the transfer of residual deformations from the section level to the element level. Actually, both residual displacements (at the section and at the element level) can be accepted, which further skips the need for iterations during the element-section state determination

$\uparrow \mathrm{FB}$ elements always provide the exact solution for frame problems since the corresponding interpolation functions satisfy the beam equilibrium equations exactly (i.e., in a strict sense), irrespective of the material constitutive behavior (even if highly nonlinear), which explains the formulation appropriateness for nonlinear analysis

$\uparrow$ Direct (exact) consideration of the effects of span loads

$\uparrow$ No meshing is theoretically required, i.e. only a single FE is required to model each structural member

- It provides a more flexible prediction of the objective ('exact') response

- The analyst should evaluate whether, in order to build a proper mass matrix for dynamic loadings, more than one element should be used

- Localization takes place in only one integration section (the one where the demand is higher). There are a few regularization techniques available to obtain objective results, which require the specification of the real plastic hinge length address herein all such hybrid proposals, they inevitably share some of the advantages and limitations of the enveloping approaches. Furthermore, the whole spectrum of mathematical models should be looked upon as being composed of complementary — rather than alternative - tools, as there is not an optimal approach as such. For example, in the absence of detailed knowledge about a member or a structure, the most judicious decision is arguably to carry out simple PHA to obtain estimates of possible bounds of the inelastic response; setting up a refined finite element model will most likely ask for unknown (and therefore questionable) assumptions on detailing or mechanical characteristics, and the resulting 'detailed' outcome will be as trustworthy as the 'unrefined' plastic hinge output. A similar type of rationale can also be found in current assessment codes [5].

The third group of observations addresses issues regarding the different levels of analysis. The inner one, for all modelling approaches corresponds to the material constitutive relations. The next level in the hierarchy of analysis is the sectional level (herein considered as a local level as well), which is shared by both the PHAs and the DPMs. However, PHA requires a simplified approximation for the moment- 
curvature relation, traditionally in a bilinear form, whilst DPMs take into account the complete sectional response, considering additionally the explicit and load-dependent interaction between axial force and bending moment(s). Another fundamental difference between the two modelling approaches — which again emphasizes the approximate character of the plastic hinge models-lays in the link between the local and the global levels of analysis:

- Plastic hinge analysis. After over half a century of proposals on mathematical models for this modelling technique, a universally accepted methodology for PHA has not yet been agreed upon. For a review on the history of PHA models the reader is referred to Hines [38]. It is acknowledged that the top lateral displacement of a RC cantilever wall is comprised of flexural, shear and slip displacements. In classical plastic hinge analysismainly directed to the analysis of members with large shear span ratios - shear and slip displacements are often neglected. ${ }^{1}$ The remaining total flexural displacement is composed of yield and plastic components, which are computed on the basis of assumed curvature profiles along the member height. They have been the subject of different proposals [37], which produce distinct estimates of both yield and plastic displacements. Such differences are mainly related to: (i) the fact that the assumed curvature profiles account differently for the influence of tensile strain penetration and the spread of plasticity caused by the presence of diagonal cracks (tension shift), and (ii) the mathematical hypotheses to compute the plastic displacements: although PHAs are based on assuming constant inelastic curvatures over an equivalent plastic hinge length $L_{p}$, some approaches consider the centre of this plastic rotation at midheight of the plastic hinge [39], while others assume it at the member end [40].

However, the most critical parameter in the link between the sectional level (i.e., yield and ultimate moments and curvatures) and the global level of analysis (i.e., yield and ultimate top lateral displacements of the member) is the formula for the equivalent plastic hinge length. It should be apparent, from the discussion above, that $L_{p}$ : (i) is a fictitious semi-empirical length from which the plastic displacements can be computed, calibrated to match the results of a selected database of experimental tests, and (ii) depends on the hypotheses of the PHA model, in particular the assumed curvature profile, deformation mechanisms considered, type of material and members forming the database (beams, columns, walls), etc; (iii) equivalent plastic hinge length, strain limits and PHA formulations should only be used in combinations

\footnotetext{
${ }_{1}^{1}$ Proposals for plastic hinge analyses wherein shear displacements are accounted for will be analysed in the present document.
}

that were calibrated against experimental results. Unfortunately, applications on earthquake engineering often tend to employ indistinctly the many existing formulae for $L_{p}$, without regards for the corresponding assumptions of the mathematical model. This is currently one of the main problems associated with this modelling approach.

Terminological misuses have however seen other regrettable developments. In fact, the very large number of proposals for the equivalent plastic hinge length [41] has led many authors to simplify the term to 'plastic hinge length', therefore eliminating the explicit reference to the equivalent character of $L_{p}$ and the reminder of the fictitious (conventional) nature of this quantity. This has opened the doors to using it interchangeably with the original concept of plastic hinge length (reworded for clarity: 'length of the plastic hinge'), which is a somehow measurable or observable physical length. In the present document, in order to clearly distinguish between the two quantities above, the latter will be referred to as real (as opposed to equivalent) plastic hinge length. The absence of an internationally accepted definition for the real plastic hinge length has further aggravated this flawed fusion of meanings.

The previous status quo has constrained some researchers to consciously avoid altogether the term 'plastic hinge length' as a synonym of the real length of the plastic hinge. Alternative nomenclatures have therefore emerged, often related to flexure-controlled members: some authors mention a 'length of plastification' that represents the actual length over which the 'real distribution of plastic curvatures' extend [42]; others use the expression 'critical region length', defined as 'the extent of the member region that needs to be confined effectively by transverse reinforcement so that the member can behave according to the performance level (in terms of flexural ductility) set by the designer' [43]; others, still, use the expression 'severely damaged region' [44], or opt for the even more general and less compromising designation of 'characteristic length', taken as the 'physical size of the region into which the strain can localize and the dissipative softening effects take place' [45].

From the regulatory standpoint, it is noteworthy that the New-Zealand code and commentary $[46,47]$ specifically differentiate between the two concepts above, by using the term 'potential plastic hinge (region) length' or 'ductile detailing length' for the real plastic hinge length, and the term 'effective plastic hinge (region) length' for the equivalent plastic hinge length. Those documents explicitly underscore that the latter is generally less than half of the former. The real plastic hinge length is denoted in the American code [48] by 'plastic hinge region', while 
it is called 'length of the critical region' or 'dissipative zone' in the European norms [12].

It is noted that although an established definition for the real plastic hinge length is still missing [43], it should reflect the damaged member region wherein spalling of concrete cover with penetration into the core region is observed, as well as local buckling or yielding of longitudinal rebars, and/or yielding of transversal steel.

- Distributed plasticity models. In this category of models it is not necessary to specify a value for the plastic hinge length to connect the local level of analysis to the global (element) level of analysis. This comes out as a consequence of the employed formulations (see Table 2 for details on the two main approaches), which allow the spread of inelasticity throughout several control sections along the member. Phenomena such as strain penetration or tension shift, which are in general indirectly accounted for in the equivalent plastic hinge length for PHAs, would have to be considered separately for distributed plasticity models but standard approaches are yet to be established. Shear and slip deformations also require ad hoc modelling techniques.

However, DPMs are not exempt from the consideration of a quantity related to the formation of a plastic hinge. This is due to the occurrence of a numerical feature named localization, which shows up after the peak of the moment-curvature curve (in the controlling section wherein it is first attained), i.e. during the softening part of the response. In order to counteract this phenomena, a regularization method should be applied. Unfortunately, this is often not available in standard finite element codes. Regularization requires the specification of a regularization length [45-47], which should be the real plastic hinge length and not the equivalent plastic hinge length, as discussed above. The occurrence of localization will be addressed later in detail.

Finally, it is noted that nonlinear geometrical effects were explicitly considered in the numerical examples addressed later with distributed plasticity models and refined membrane models [51,52]. However, they play a negligible role for the considered case studies.

\section{Dependability: Strain Limits, Localization, and Numerical Issues}

The outcome of finite element analyses should be interpreted with a critical eye in order to identify the physically meaningful - herein named dependable - part of the response. This range of results is bounded by one of the following scenarios, whichever occurs at a lower value of drift: (i) a material strain limit is reached, that is assumed as the threshold beyond which the constitutive relation defined in the software is no longer representative of the true material behavior; (ii) localization occurs, i.e., a numerical feature inducing mesh-dependent results; (iii) other numerical issues take place, rendering the output untrustworthy. In short, the above mentioned conditions can be expressed as:

$$
\begin{aligned}
& \text { Dependability Upper Bound } \\
& =\min \{\text { Material Strain Limit, Localization, } \\
& \text { Numerical Issues\} }
\end{aligned}
$$

In this document, the material strain limit (MSL), which defines the limit of applicability of the constitutive relationship, is taken as the damage control limit state (DCLS) defined by Priestley et al. [40]. The corresponding concrete compression and steel tension strain limits are:

$$
\begin{aligned}
\varepsilon_{c, d c} & =0.004+1.4 \frac{\rho_{y} f_{y v} \varepsilon_{s u}}{f_{c c}^{\prime}} \\
\varepsilon_{s, d c} & =0.6 \varepsilon_{s u}
\end{aligned}
$$

where $\rho_{v}$ and $f_{y v}$ are the volumetric ratio and the yield strength of the transversal reinforcement, $\varepsilon_{s u}$ is the monotonic steel strain at maximum strength and $f_{c c}^{\prime}$ is the compression strength of confined concrete. Equation (1), obtained by equating the increase in strain energy absorbed by the concrete to the strain capacity of the transversal steel [53], aims at estimating the strain at which fracture of the transverse reinforcement confining the concrete core occurs. This expression is based on pure axial compression of the core concrete and should therefore yield a conservative estimate for flexural loading. Eq. (2), on the other hand, sets the steel strain limit to $60 \%$ of the ultimate capacity to account for the possible occurrence of buckling and low cycle fatigue, which is not considered by the chosen constitutive relationships. As stated above, these limits should be regarded as model-specific criteria. In fact, they only represent a bound for the concrete and steel constitutive laws considered in this study that are discussed in Sect. 6.2. For instance, if buckling or low cycle fatigue are explicitly incorporated in the steel model, one can arguably set a higher value for the limit $\varepsilon_{s, d c}$.

As a side comment, it is noted that local-level limits can be imposed in terms of strains-such as the ones in Eq. (1) and (2) or others [54,55] - or alternatively in terms of curvatures, as suggested by Kazaz et al. [56]. Naturally, the latter can only be applied directly to those modelling techniques wherein the sectional level of analysis is considered (i.e., PHAs and DPMs) but are not easily applicable to SEMs. For this reason, curvature limits are not considered in this study.

As inelasticity demand increases, the analysis dependability can also be controlled by numerical problems. As mentioned above, they are herein divided in two main groups, named 'Localization' and 'Numerical Issues'. This separa- 
tion was carried out because the former phenomenon, yielding non-objective results related to the finite element formulation, has a physical counterpart that should ideally be simulated by a regularization method [57,58]; an example for the physical behavior is crushing of the concrete over a critical length at the wall base. The term 'Numerical Issues', on the other hand, stands for a variety of additional numerical problems without physical equivalency that lead to senseless outputs; they are harder to tackle in detail since they are usually linked to software-specific features, e.g. solution algorithm, convergence and tolerance criteria, numerical instabilities, implementation of material models, etc. Both groups are illustrated within the framework of the case study in Sect. 6.5.

\section{Modelling of Shear Deformation}

As stated before, shear deformations in wall-type structures can constitute a significant portion of the total deformation and thus should in general be modelled. A review of results from quasi-static cyclic tests on RC walls showed that the ratio of shear to flexural deformation remains approximately constant if the wall is developing a dominating flexural mode and increases if it is a shear mode instead [59]. For walls subjected to in-plane loading that failed in flexure and had shear span ratios larger than 2.0, the ratio of shear to flexural deformations determined from experimental results varied between 5 and $40 \%$ and depended mainly on the ratio of compression zone depth to wall length and shear span ratio [59]. The relatively crude rule-of-thumb $L_{s} / h>3$ is useful to select members wherein the impact of shear deformations on global EDPs will be typically small and can possibly be neglected [40]. If the ratio of shear to flexural displacements is less than approximately $10 \%$, its effect on EDPs in statically determined systems is typically small. Note, however, that the shear flexibility can influence the force distribution in statically indetermined systems even if the shear flexibility is low $[29,32]$. Shear deformations, as well as shear-flexure interaction, can be accounted for in different ways depending on the chosen modelling approach [60]. Hereinafter they are briefly discussed for PHA, DPMs, and SEMs.

Three well-known methods of PHA accounting for shear deformations available in the literature are now addressed. They are based on the observation that the shear to flexural deformation ratio $\left(\Delta_{s} / \Delta_{f}\right)$ of flexure-dominated walls is roughly constant in the inelastic phase of the response [61]. A first proposal for the evaluation of the abovementioned ratio was made by Hines et al. [62], as a function of the shear span ratio, the crack angle, and a correction factor accounting for the increase in shear deformations due to poor transversal reinforcement or thin webs. More recently, Priestley et al. [40], based on the work of Miranda et al. [63], suggested a method that takes into account three different stages of the response: (i) prior to shear cracking, elastic shear stiffness is proportional to the reduction in flexural stiffness; (ii) inbetween shear cracking and the attainment of the nominal flexural strength, shear stiffness is computed according to the strut and tie model proposed by Park and Paulay [64]; (iii) in the inelastic range, the ratio $\Delta_{s} / \Delta_{f}$ is assumed to be constant. Finally, the equation proposed by Beyer et al. [59] accounts for the curvature demand, crack angle, shear span, and the novel additional influence of the mean axial strain in the shear deformations. The latter is the method adopted for the case study in Sect. 6.2. Several LPMs, as finite element counterparts of PHA, can obviously also account for shear deformations and flexure-shear interaction through similar or alternative assumptions $[60,65,66]$.

For DPMs, the consideration of shear deformations requires an extension of the classical Euler-Bernoulli beam theory hypothesis, i.e. plane sections can no longer be assumed perpendicular to the deformed beam axis. Hence, a Timoshenko framework is generally considered, either associated to a displacement-based formulation [26,67-69] or a force-based approach [70-72]. Timoshenko hypothesis implies a constant shear strain profile throughout the section. However, other more advanced shear strain profiles have also been considered in the literature, for instance parabolic patterns which satisfy equilibrium during elastic behaviour [73]. Additionally, coupling between shear and flexural deformation mechanisms was also modelled in a simplified way with displacement-based [74] and forcebased element approaches [75,76]. Research in this topic is an ongoing effort, as proven by recent proposals featuring higher-order force-based beam formulations [77, 78]. Unfortunately, most of the previous proposals are not readily available in existing structural analysis software and thence they were not considered in the present study.

In SEMs, the shear deformations are directly accounted for by the membrane element formulation, which requires a bidimensional or tridimensional constitutive model. In the application example, simulated with VecTor2 [21], a plane stress rectangle is used in association with the Modified Compression Field Theory [79] and the Disturbed Stress Field Theory [80].

\section{Accounting for Confinement in Different Approaches}

The effect of active and passive confinement of concrete has raised the interest of researchers since the 1920s [81]. Confinement increases the strength and the deformation capacity of concrete. However, it also plays a role in other phenomena such as the brittle-to-ductile transition [82], after which the failure surface and the residual strength surface coincide. The way to account for confinement effects depends 
on the framework wherein the concrete constitutive model is developed: nonlinear elasticity, plasticity theory, damage theory, fracture mechanics, etc. Therefore, the three modelling approaches employed in this study (PHA, DPMs, SEMs) ask for distinct considerations.

The computation of the sectional response in PHAs and DPMs requires the cross-sectional integration of uniaxial stress-strain curves defined for each concrete fibre. Those relations are adjusted through confinement models, which typically use a coefficient to compute the compressive strength of confined concrete $f_{c c}^{\prime}$ from the specified cylinder strength $f_{c}^{\prime}$. That coefficient depends on the passive confinement produced by the reaction of the transverse reinforcement to the lateral expansion of the concrete. A distinct coefficient, also function of the confining stresses, allows obtaining the confined concrete strain at maximum strength $\varepsilon_{c c}$ from its unconfined counterpart $\varepsilon_{c}$.

Many uniaxial concrete models assume that such confining stresses (and strains) are similar in the two lateral directions [83]. However, indications are often missing on how to derive this uniform lateral pressure for the case of RC members such as walls. Other proposals, where confining stresses are also assumed to be identical in both directions, do however provide explicit recommendations in that regard, e.g., the one proposed by Cusson and Paultre [84]. The renowned model by Mander et al. [53] considers the possibility of having different confining stresses in the two lateral directions, and indicates how to compute them for RC members. The failure surface described by Willam and Warnke [85] is then used to obtain $f_{c c}^{\prime}$. The corresponding strain is obtained following the indications of Richart et al. [81]. This model is of more straightforward application than the model by Cusson and Paultre [84], and will thus be adopted for the case study.

It is noted that the simpler form of the model by Mander et al. [53] is mainly related to the assumption that the lateral confining pressure is developed from equilibrium with transverse reinforcement at yield. Such hypothesis is not considered in the work by Cusson and Paultre [84], who use an iterative approach to compute the stress in the transverse reinforcement at the peak concrete strength. The introduction of the previous adjustments were based on the findings by Cusson and Paultre [86], who showed that the yield strength may not be reached with low confinement or when transverse reinforcement is made of high-strength steel. A more recent improvement of the model, made by Légeron and Paultre [87], proposes a direct procedure to compute the transverse reinforcement stress and consequently the equivalent confinement pressure.

Most uniaxial concrete models for RC behaviour make use, in general, of a geometrical effectiveness coefficient of confinement. Originally developed by Sheikh and Uzumeri [88], it reflects the effectiveness of the transverse reinforcement in confining the concrete and accounts for the fact that the maximum lateral pressure due to transverse reinforcement is not uniformly applied throughout the volume of the concrete core. Midway between the layers of transverse reinforcement, the area of effectively confined concrete is minimal due to arching action and can be computed from the spacing and tie configuration.

Regarding the confinement effects in the SEMs, the enhancement of strength and ductility in the bidimensional concrete constitutive relation will be addressed in greater detail in Sect. 6.7.

\section{Application Example}

In engineering practice, numerical tools are used to simulate the expected behaviour of structures. The objective of this section is to analyse a case study wall using modelling techniques commonly applied in engineering practice-namely PHAs, DPMs, and SEMs - and compare the resulting global and local EDPs. In order to make the modelling approaches comparable and not to inadvertently 'compensate', for example, differences in element formulations with differences in constitutive relations, the authors have made the models as coherent and comparable as possible. The details of this process will be thoroughly addressed in the following sections. In some cases, it entailed the conscious decision of not exploring the full potential of a particular modelling approach, as it will be discussed below. The prediction of the actual wall response thus only comes as a secondary aim of the following examples.

\subsection{Case Study}

The cantilever wall herein analysed depicts the effective height of a $2 / 3$ scale RC wall representing a typical Swiss building of the 60s. This wall is part of a series of tests on thin RC walls, carried out between September 2013 and October 2014 at the structural engineering laboratory (GIS) of the École Polytechnique Fédérale de Lausanne (EPFL). Estimates of the wall responses were required in order to assist with the preparation of the experimental program, giving rise to the current study. The geometry and reinforcement layout of the reference test unit are illustrated in Fig. 1. Although the specimen represented in the figure corresponds to the first story, the effective height was simulated in the experimental test setup by the application of a top bending moment, coupled to the lateral displacement. Further information on the experimental program can be found in [89].

The wall section length was $h=2.7 \mathrm{~m}$ and its thickness $t=0.12 \mathrm{~m}$. It featured a small-dimension flange at one of the edges simulating the presence of a perpendicular member. The longitudinal and transverse reinforcement were constituted by $6 \mathrm{~mm}$ diameter rebars uniformly spaced 


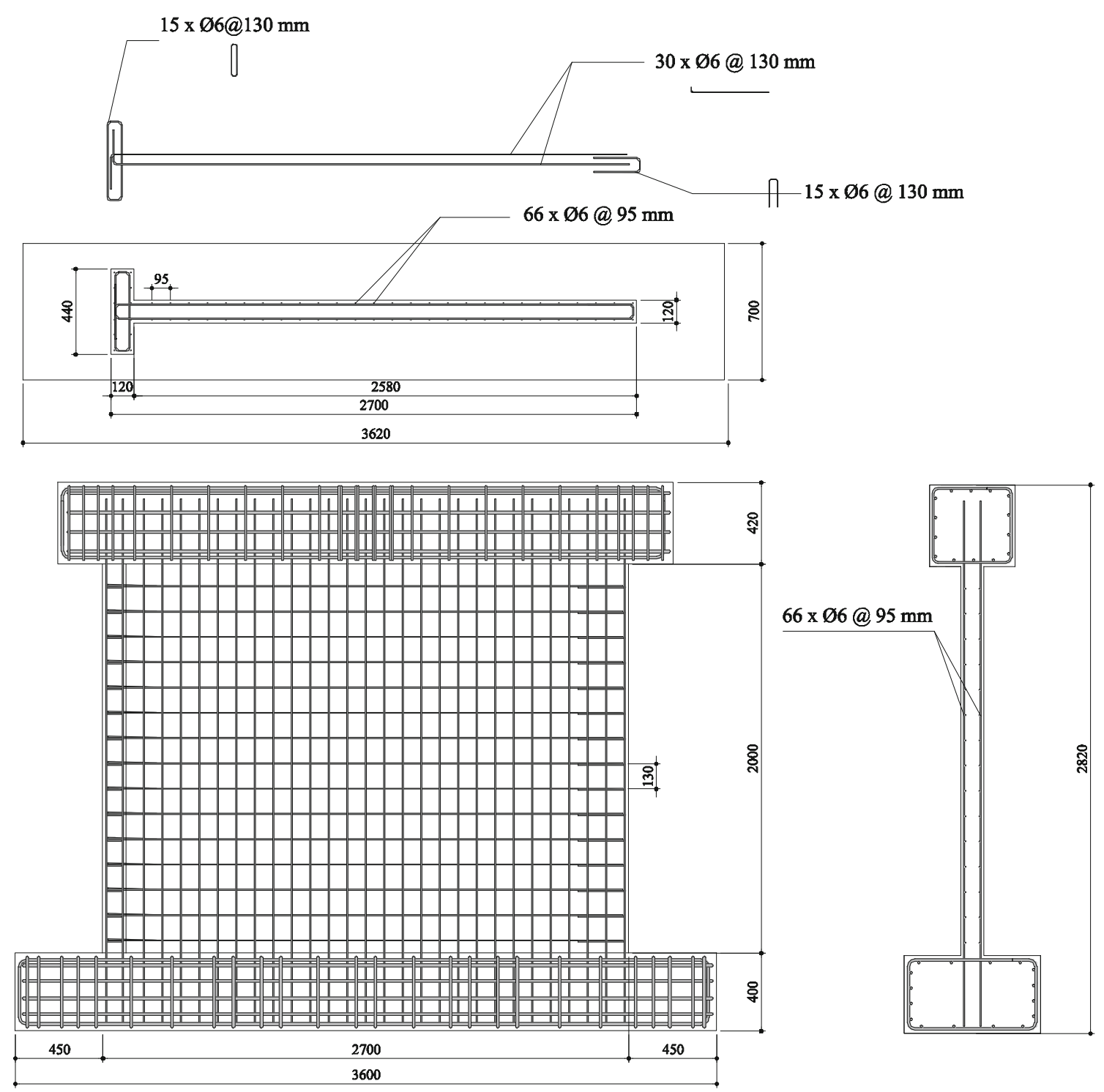

Fig. 1 Geometry and reinforcement layout of the test unit (all dimensions in millimeters)

respectively at $95 \mathrm{~mm}$ and $130 \mathrm{~mm}$. The clear concrete cover was $15 \mathrm{~mm}$.

The mechanical features of the reinforcing steel were obtained by carrying out six uniaxial tension tests, whose mean stress-strain curve is shown in Fig. 3b. As it can be seen, there is no evidence of yield plateau, hence for modelling purposes the tensile strain at the beginning of the hardening curve, $\varepsilon_{s h}$, was assumed to coincide with the yield strain $\varepsilon_{s y}$. The ultimate strain $\varepsilon_{s u}$ was evaluated as the total steel elongation at maximum force. On the other hand, the concrete mechanical properties were not available at the time of the present work. Consequently, the cylinder strength $f_{c}^{\prime}$ was assumed as the one requested to the concrete manufacturer. The modulus of elasticity was estimated as $E_{c}=4700 \sqrt{f_{c}^{\prime}}$
[90]. Finally, a standard value for the concrete strain $\varepsilon_{c}$ at maximum stress was used, whilst the concrete tensile strength $f_{t}^{\prime}$ was computed according to Lin and Scordelis [91] $f_{t}^{\prime}=0.34 \sqrt{f_{c}^{\prime}}(\mathrm{MPa})$. The reinforcement ratios and the mechanical properties of the employed materials are summarized in Table 3. These data, together with the geometry of the wall, contains all the input required to set up the models for this study.

In order to assess the relative significance of shear deformations in the structural behaviour, three different shear spans were considered: $L_{s}=2.1 \mathrm{~m}, L_{s}=4.2 \mathrm{~m}$, and $L_{s}=$ $8.4 \mathrm{~m}$, corresponding respectively to 1,2 and 4 times the height of the test unit. The resulting shear span ratios $L_{s} / h$ are $0.78,1.56$, and 3.12. In all the cases a constant axial 
Table 3 Mechanical characterization of the wall: reinforcement ratios and material properties

\begin{tabular}{|c|c|c|c|c|c|c|}
\hline & \multicolumn{3}{|c|}{ Reinforcement ratios } & & & \\
\hline & $\begin{array}{l}\text { Vertical } \\
\rho_{v}(\%)\end{array}$ & $\begin{array}{l}\text { Horizontal } \\
\rho_{h}(\%)\end{array}$ & $\begin{array}{l}\text { Orthogonal* } \\
\rho_{\text {ort }}(\%)\end{array}$ & & & \\
\hline Web & 0.49 & 0.35 & {$[-]$} & & & \\
\hline \multirow[t]{3}{*}{ Flange } & 0.64 & 0.19 & 0.35 & & & \\
\hline & \multicolumn{4}{|c|}{ Material properties } & & \\
\hline & $f_{c}^{\prime}(\mathrm{MPa})$ & $\varepsilon_{c}(\% 00)$ & $E_{c}(\mathrm{MPa})$ & $f_{t}^{\prime}(\mathrm{MPa})$ & & \\
\hline \multirow[t]{2}{*}{ Concrete } & 37 & 2 & 28600 & 2 & & \\
\hline & $f_{y}(\mathrm{MPa})$ & $f_{\boldsymbol{u}}(\mathrm{MPa})$ & $E_{s}(\mathrm{MPa})$ & $\varepsilon_{s y}(\% 0)$ & $\varepsilon_{s h}(\%)$ & $\varepsilon_{s u}(\%)$ \\
\hline Steel & 484 & 610 & 210000 & 2.3 & 2.3 & 82 \\
\hline
\end{tabular}

* The orthogonal reinforcement corresponds to the wall out-of-plane direction

load $N=690 \mathrm{kN}$-equivalent to an axial load ratio of $N /\left(f_{c}^{\prime} \cdot A_{g}\right) \cong 5 \%\left(A_{g}\right.$ is the gross sectional area $)$-was applied at the top of the wall, at its centroid.

The presentation of results corresponding to detailed analyses in the two directions of loading would only be justified if it would bring an additional relevant insight to the comparison between the modelling approaches. Since that was not the case, and in view of space limitations, it was decided to just include the results for the case where the flange is in tension.

\subsection{Modelling Approaches}

As mentioned already, three different modelling techniques were used to predict the response of the cantilever wall described in the previous section. As indicated in Table 1, they rank in ascending order of complexity as follows: plastic hinge analyses (PHAs), distributed plasticity models (DPMs) and shell element models (SEMs). The specificities of each model employed in the analyses are thoroughly described in the following paragraphs.

Two plastic hinge models were considered. The first, which does not account for shear deformations, is based on the flexural PHA formulation proposed by Priestley et al. [40], with the adaptations therein suggested for wall-type structures. The equivalent plastic hinge length is expressed as:

$L_{p}=k L_{s}+0.2 h+L_{s p} \geq 2 L_{s p}$

where $k$ is a factor accounting for the spread of plasticity due to strain hardening of the reinforcement, $L_{S}$ is the shear span (distance from the point of contraflexure to the critical section of the member), $0.2 h$ is an additional term accounting for the effect that tension shift plays on walls, and $L_{s p}$ is the strain penetration length which is given by:
$L_{s p}=0.22 f_{y l} d_{b l}$

with $f_{y l}$ and $d_{b l}$ being the yield strength and diameter of the longitudinal reinforcement. The ultimate flexural displacement is the sum of the yield and plastic flexural displacements:

$$
\begin{aligned}
\Delta_{u}= & \Delta_{y}+\Delta_{p}=\frac{\phi_{y}}{3}\left(L_{s}+L_{s p}\right)^{2} \\
& +\left(\phi_{u}-\phi_{y}\right) L_{p}\left(L_{s}-\left(0.5 L_{p}-L_{s p}\right)\right)
\end{aligned}
$$

The yield and ultimate curvatures were obtained from the bilinear idealization of the moment-curvature curve. The damage control strain limits, as defined in Sect. 3, were used to define the ultimate curvature. The sectional analysis was performed with the open source software OpenSees [20]-herein labelled as 'OS' — discretising the section into 200 fibers. Cover and core concrete were modelled using the library uniaxial material 'Concrete 04', which is based on the model proposed by Popovics [92]. The mechanical properties of the core concrete were determined according to Mander et al. [53] with a geometrical effectiveness coefficient of confinement $C_{e}=0.5$, as recommended by Priestley et al. [40] for wall-type elements. The obtained values for the confined concrete maximum strength and the corresponding strain were $f_{c c}^{\prime}=41.3 \mathrm{MPa}$ and $\varepsilon_{c c}=3.16 \%$ respectively. The Dodd Restrepo model was used for the reinforcement bars because, as shown in Fig. 3b, it represented the solution that best fitted the experimental data. Rebar buckling was not considered in the model.

The second PHA model, which accounts for shear deformation, was the one developed by Beyer et al. [59]. The ratio of shear-to-flexural deformation can be expressed as:

$$
\frac{\Delta_{s}}{\Delta_{f}}=1.5 \frac{\varepsilon_{l}}{\phi \tan \theta} \frac{1}{L_{s}}
$$


Table 4 General features of distributed plasticity models (DPMs)

\begin{tabular}{lllll}
\hline Model & Element type & No. of elements & No. of integration points & Integration rule \\
\hline OS-FB-5IP & Force-based & 1 & 5 & Gauss-Lobatto \\
OS-FB-9IP & Force-based & 1 & 9 & Gauss-Lobatto \\
OS-DB-PH* & Displacement-based & 4 & 2 & Gauss-Legendre \\
\hline
\end{tabular}

* The length of the element close to the base corresponds to the equivalent plastic hinge length

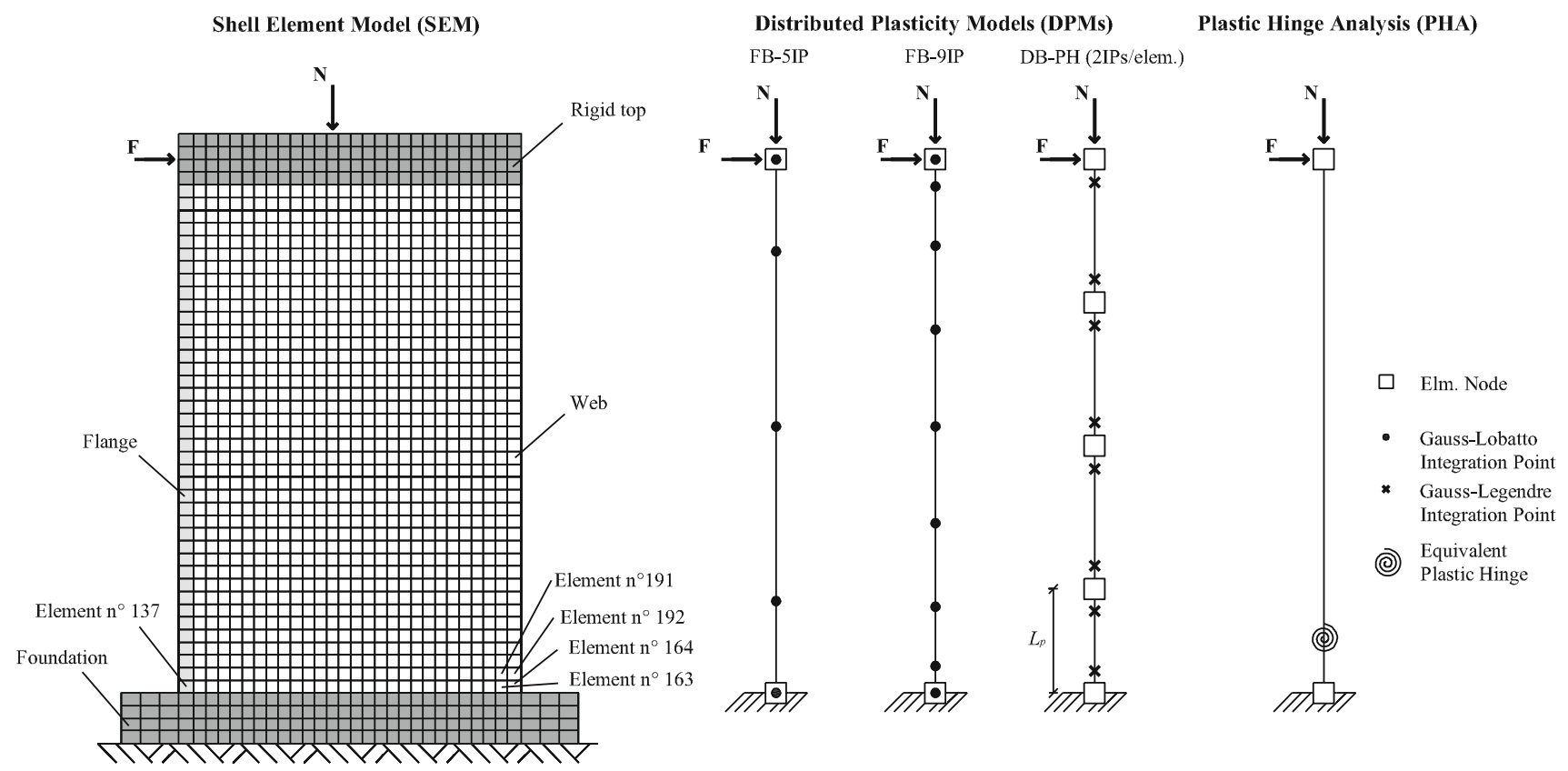

Fig. 2 Employed modelling techniques for the simulation of the wall response (SEM mesh corresponding to $\mathrm{L}_{S} / h \approx 1.56$ )

where $\varepsilon_{l}$ is the longitudinal strain along the centroidal axis of the wall, $L_{s}$ is the shear span, $\phi$ is the curvature demand. $\varepsilon_{l}$ and $\phi$ are derived from moment-curvature analysis for a maximum steel strain of $1.5 \% . \theta$ is the crack angle at the top of the fan-like mechanism which, according to Hagsten et al. [93] and used by Hannewald [94], can be expressed in function of the reinforcement ratios:

$\theta=\arctan \left(\sqrt[4]{\frac{\rho_{v}+k_{E} \rho_{h} \rho_{v}}{\rho_{h}+k_{E} \rho_{h} \rho_{v}}}\right)$

in which $k_{E}$ is the ratio between the steel and the concrete elasticity moduli, while $\rho_{v}$ and $\rho_{h}$ are the geometrical reinforcement contents in the vertical and horizontal direction.

For the distributed plasticity models (DPMs), three distinct modelling options were considered to simulate the behaviour of the cantilever wall. They differed with regard to the beam element formulation (displacement-based vs. forcebased, see Table 2), mesh discretization, and numerical integration scheme; their features are summarized in Table 4 and shown in Fig. 2.

As indicated in Table 2, force-based formulations verify exactly beam equilibrium. Therefore, only one element was assigned to model the structural member. Additionally, in order to simulate the concentration of inelasticity at the wall base, a Gauss-Lobatto quadrature is preferred to a GaussLegendre quadrature since the former features an integration point at the element end and therefore at the wall base, whilst the latter does not. During the pre-peak branch of the moment-curvature, the element response is a function of the numerical accuracy of the integration rule, and it has been shown that typically five integration points (IPs) are sufficient [95]. However, since the post-peak element response is highly dependent on the number of IPs, an additional scheme with nine IPs was also considered. On the other hand, the displacement-based model discretized the member in four elements, each one with two Gauss-Legendre IPs. The reasons for the choice of this discretization is linked to the displacement interpolation functions of the DB finite element and is based on the findings by Calabrese et al. [57]. It is noted that the length of the bottom element was defined as the equivalent plastic hinge length $L_{p}$ given by Eq. (3). From the smaller to the larger shear span, it corresponds to $0.71 \mathrm{~m}$, $0.82 \mathrm{~m}$, and $1.04 \mathrm{~m}$. Following the discussion in Sect. 2, it should be underlined that the real plastic hinge length should have been used instead of the equivalent plastic hinge length. 

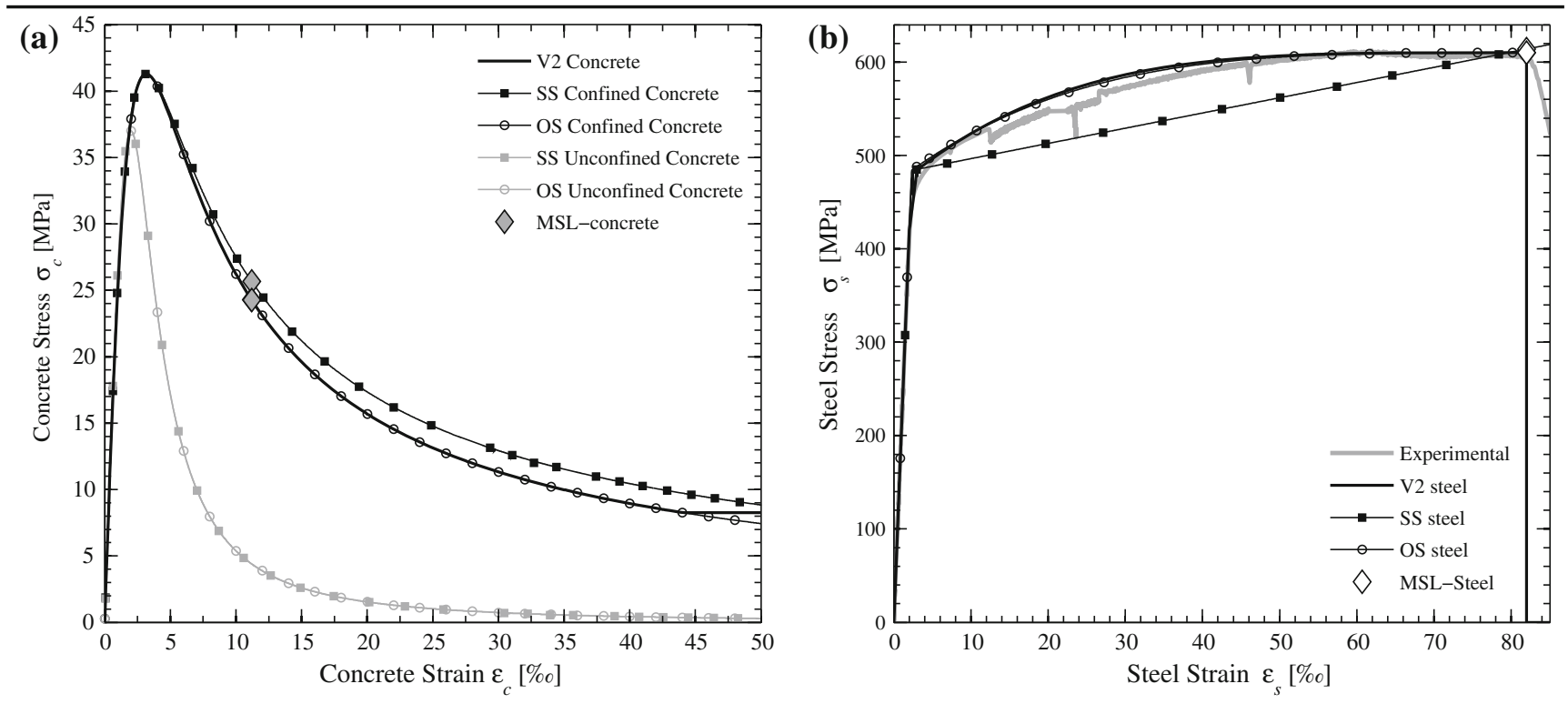

Fig. 3 Adopted material constitutive laws: a concrete, b steel (numerical vs. experimental)

The reason for this intentional incongruence is two-fold: on the one hand, the present study is simply a comparative investigation between modelling approaches, and not a validation against experimental results; on the other hand, there are still relatively few expressions in the literature for the real plastic hinge length that have been sufficiently validated.

The software used to carry out the analysis of the DPMs was OpenSees [20]. The sectional discretization and the materials employed were the same described above regarding the moment-curvature analysis. Another goal of the study was to assess the differences between existing structural analysis packages that build on distinct uniaxial material models, as well as numerical implementations of finite element formulations and respective solutions. Therefore, the case of a FB element with 5 IPs was also analysed using the FE software SeismoStruct [19]—herein labelled as 'SS' - giving rise to the model 'SS-FB-5IP'. In both Seismostruct and OpenSees, the material model used to describe the concrete follows the constitutive relationship proposed by Popovics [92]. The model matching between the concrete models adopted in OpenSees and SeismoStruct is almost perfect, as shown in Fig. 3a. On the other hand, it was not possible to find, at the time of the analyses, a steel constitutive law in SeismoStruct fitting properly the experimental results. Hence, the model by Menegotto and Pinto [96] with the isotropic hardening rules proposed by Filippou et al. [97] was employed, as depicted in Fig. $3 b$.

The shell element simulation was carried out with the 2D membrane software VecTor2 [21], designated as 'V2' in the figures, developed at the University of Toronto and based on the Modified Compression Field Theory [79] and the Disturbed Stress Field Theory [80]. The structure is discretized by plane stress rectangles (see Fig. 2) of RC material with smeared reinforcement. The monotonic steel stress-strain curve is composed of three parts: an elastic branch, a yield plateau, and a nonlinear strain hardening phase until rupture. Besides the material properties, also the reinforcement ratios in the three directions of the reference system have to be given as input. They are reported in Table 3, both for the elements of the web and flange. The concrete constitutive law in the principal compressive direction follows the stress-strain relationship proposed by Popovics [92] for normal strength concrete (as used in the OpenSees models). The cover concrete was not modelled because it was shown not to be significant neither at the global nor at the local levels at the damage control limit state. Additionally, numerical accuracy concerns recommend aspect ratios below 3:2 for membrane mesh elements, which would require an extremely fine mesh for the concrete cover in the current wall.

The base model implemented in VecTor2 considered confinement effects by assigning explicitly the same peak strength and associated strain indicated above for the sectional analyses $\left(f_{c c}^{\prime}=41.3 \mathrm{MPa}\right.$ and $\varepsilon_{c c}=3.16 \%$ ). Automatic strength enhancement due to confinement was disregarded, as well as all the other material effects available in the software (such as compression softening, tension softening, tension stiffening, dilation, etc.). This choice relates to the main purpose of this study, i.e. to compare the scatter of the response provided by different modelling techniques. Hence, the authors were primarily interested in minimizing the potential for discrepancies arising from effects at the material level that cannot be equally reproduced by all the modelling approaches. For example, if a confinement model had been ascribed to VecTor2 analyses, the concrete stress-strain relation in each element would change during loading, creating an inevitable inconsistency towards DPMs and PHAs (which have pre-defined and constant values for the confined concrete parameters in all the concrete layers). 
Fig. 4 Global-level response comparison

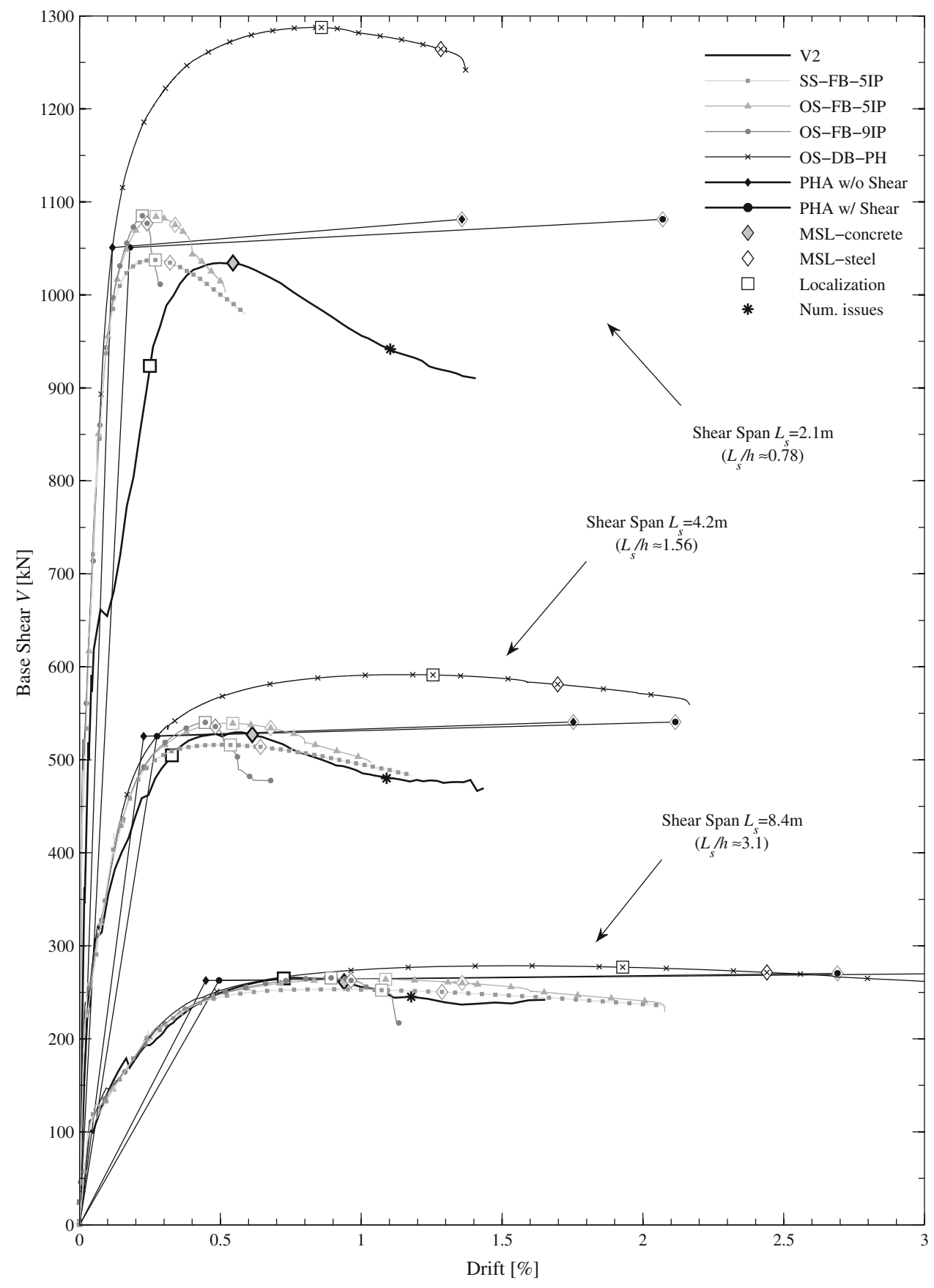

However, the conceivable influence in the wall response of different confinement models and other material effects available in VecTor2 deserved detailed analyses, which are illustrated in Sect. 6.7.

\subsection{Global-level Response}

This section presents and discusses the shear force-top displacement curves obtained for all the considered models and shear span ratios. In Fig. 4 drifts instead of top displacements are plotted on the $x$-axis to facilitate the comparison between walls of different height. For each capacity curve, the material strain limit (MSL) and the occurrence of localization (as defined in Sect. 3) are explicitly indicated. Different markers are used to indicate the attainment of the concrete or steel MSLs. For the case study, they correspond to a core concrete strain $\varepsilon_{c c}=11.2 \%$ and of a longitudinal reinforcement strain $\varepsilon_{s}=49.2 \%$ [40]. The onset of localization, which will be discussed in detail in Sect. 6.5, is identified with a marker indicating the limit of response objectivity. For the shell element model (SEM), an additional point defining the onset of numerical issues is displayed. In fact, although 
the global capacity curves resulting from the SEMs show a smooth behaviour until the end of the analysis, it will be seen in Sect. 6.5 that there is a drift beyond which the global results build on an unstable 'waggling' local behaviour. Hereinafter the results are presented and discussed for decreasing values of the shear span ratio. A few general comments are however due, which hold for all the considered cases.

Firstly, it is noted that the MSLs are attained after the occurrence of numerical localization, as discussed in Sect. 6.5. In other words, these cases illustrate that performance-based assessments relying solely on material limit strains may be untrustworthy. Secondly, it is apparent that, apart from the SEMs wherein shear can assume a relevant role, the steel MSL is the governing condition. Further details can be found in Sect. 6.6. Thirdly, for DPMs with one FB element and five IPs, the differences between the models in OpenSees (OS) and SeismoStruct (SS) can be imparted to the distinct steel constitutive laws; the SS lower-bound stressstrain relation, see Fig. $3 b$, reflects in a lower-bound prediction of the associated force-displacement curves. Finally, concerning the OS results, it is observed that the curves for 5 and 9 IPs start diverging in the post-peak branch following the localization onset (Sect. 6.5).

Regarding the results corresponding to the shear span ratio $L_{S} / h \approx 3.1\left(L_{s}=8.4 \mathrm{~m}\right)$, a good agreement amongst all the proposed models can be found. The scatter in the predicted lateral capacity of the wall is below $10 \%$, and the stiffness evolution up to the peak strength is very similar for all models. The exception is obviously the PHA models, which-due to the underlying bilinear moment-curvature assumptionexhibit a constant stiffness up to the yield point (see Sect. 6.2). As discussed previously, for shear span ratios $L_{S} / h>3$, shear deformations are expected to play a marginal role [40]. That can be confirmed by the similarity of the predictions given by the two PHA models and by the agreement between the DPM responses, which neglect shear deformations, and the SEM results, which include shear deformations. Taking the SEM force-displacement curve as benchmark, the DPMs using force-based (FB) elements appear to give better results than the one employing displacement-based (DB) elements. The latter, although providing good estimates of the wall force capacity, grossly overestimate its displacement ductility capacity (reasons discussed in Sect. 6.4).

Looking at the case of $L_{S} / h \approx 1.56\left(L_{S}=4.2 \mathrm{~m}\right)$, shear deformations are no longer negligible and their effect on the global response of the wall becomes rather apparent: first off, the SEM capacity curve depicts an increased flexibility in relation to the DPM results; furthermore, the PHA accounting for shear displays a $20 \%$ higher ultimate drift than the purely flexural PHA. It is observed that the latter-although not applicable to the current case due to its low shear span ratio-was included for comparative purposes against the PHA that accounts for shear. The figure also shows that the
DB approach deviates significantly from the remaining models, not only in terms of ductility but also in terms of lateral strength prediction (30\% higher than the SEM). Such observation does not come as a surprise since DB formulations provide stiffer and stronger predictions of the actual member response due to the assumption of displacement interpolation functions (Table 2) [98]. An objective ('exact') response can only be obtained with a larger number of DB elements. In particular, it is advisable to adopt a small length for the elements wherein the member demand is higher. This condition is not met in the present case since the base element length corresponds to the equivalent plastic hinge length (as calculated for PHAs), which represents about $20 \%$ of the wall height. The remaining modelling techniques yield relatively similar predictions of the wall capacity and of the drift at peak strength.

The overall behaviour described above for the intermediate shear span is even more pronounced for the case of $L_{s} / h \approx 0.78\left(L_{s}=2.1 \mathrm{~m}\right)$, due to the increased influence of shear. To start with, it is noted that the results obtained with both PHA models (with and without shear) and DB elements are of little physical meaning. In fact, the assumptions of PHA - as discussed in Sect. 2-are not applicable to such small shear span ratio, where the equivalent plastic hinge length represents more than $30 \%$ of the wall height. A somewhat similar justification can be ascribed to the DB results, wherein the disproportionate length of the base element used in the discretization prevents a suitable simulation of the distribution of inelasticity (which explains the consequent increase of strength and displacement predictions). Regarding the comparison between the SEM and the FB approaches, and notwithstanding the acceptable simulation of the member force capacity, the clear influence of shear deformations show that Euler-Bernoulli beam theory is no longer acceptable.

\subsection{Local-level Response}

The local-level response of the wall is now depicted and interpreted for each model and shear span ratio. The vertical strains of both the compressed concrete core and steel in tension are presented respectively in Fig. 5a, b (note the distinct scales in the abscissa). The horizontal grey dashed line defines the concrete and steel MSLs. As discussed in Sect. 2, the results obtained from the PHAs are not presented since local EDPs (e.g. strains) should not be back-calculated from the results obtained at the global level. Concerning the DPMs, the strains of the extreme fibres are recorded at the section corresponding to the bottom IP. It is recalled that the position of such section corresponds to the member base for the FB model (since a Gauss-Lobatto integration scheme is used) and the bottom Gauss-Legendre point for DB models, which in the present case is $0.21 \times L_{p}$ above the base. This can be observed in Fig. 2, which also depicts the posi- 
tion and number of the elements in the SEMs wherein the vertical strains are tracked. In this latter category of models, several neighbouring elements are monitored for the concrete strains since the response amongst them differs significantly, due to the occurrence of localization. Section 6.5 will provide further insights into this numerical problem, which is not evident on the tensile wall side due to the low absolute values of concrete tensile strength; therefore, only the steel vertical strains at one element need to be recorded. Similarly to the global-level response, the points corresponding to the MSLs and the onset of localization are indicated in each curve.

The first fundamental observation from Fig. 5 is that the scatter of the strain predictions with the different modelling approaches progressively increases with the level of drift. This is not surprising since strains are highly dependent on the assumptions of the finite element formulation and the deformation mechanisms that they account for. The current numerical example thus shows that the use of strain-based EDPs should always be carefully employed for assessment purposes, and straightforwardly disregarded beyond certain values of drift. In order to define the latter threshold, it is essential to consider the dependability range of the analyses; this, as discussed in Sect. 3, was defined by the attainment of strain limits, localization onset, or numerical issues, whichever occurs first. It pinpoints a bound above which the simulation becomes progressively or immediately nonsensical.

The second general remark relates to the scatter of the strain values at the same level of drift: the simulation scatter of the concrete and steel vertical strains increases with the decrease of the shear span ratio. As an example, for the wall with $L_{S} / h \approx 0.78$, the ratio between the upper and lowerbound concrete vertical strain estimates given by different modelling approaches at a drift level of $0.2 \%$ is around five. For the wall with $L_{S} / h \approx 3.1$, the same ratio can be found at a drift level of approximately $1 \%$ (i.e., 5 times larger).

Other comments can be obtained by analysing the strain curves within each plot of Fig. 5 in more detail. For what concerns concrete, an overall comparison of the SEM curves for the four bottom corner elements show a first evident disagreement: after the localization onset, the strains concentrate in the elements no. 163 and 164 of row 1 above the foundation, while elements no. 191 and 192 of row 2 above the foundation show a general unloading trend. The reasons for this behaviour will be analysed in the next section, which will also shed light on the deviation of the FB results for different number of integration points after the onset of localization. On the other hand, it is also apparent that the DB model grossly underestimates the vertical strains when compared to the FB approach. This discrepancy, which decreases for larger shear span ratios, is attributable to the DB beam element formulation; namely, the assumed linear curvature profile along each element length, associated with an average verification of equilibrium, creates an artificial restraint in the development of inelastic curvatures amongst the IPs [57]. Regarding the steel strains predicted by the DPMs, analogous observations can be made; it is however noted that, for all the considered shear span ratios, the prediction given by the SEM defines the lower-bound (see Sect. 6.6).

To complement the information at the local level, a comparison of curvature profiles along the wall height is shown in Fig. 6. The results, which refer to the most flexure-dominated case $\left(L_{S} / h \approx 3.1\right)$, are plotted for the drift at peak base shear of the SEM (0.8\%), as well as for pre-peak (0.5\% drift) and post-peak (1.1\% drift) states. The curvatures for the SEM were obtained dividing the difference of the vertical strains at the two wall edges by the wall length.

In the pre-peak case, one notices a rather good agreement amongst the different models. At the base, the curvature values vary between $\phi_{V 2}=2.5 \mathrm{~km}^{-1}(\mathrm{SEM})$ and $\phi_{S S}=4.3 \mathrm{~km}^{-1}$ (DPM in SS-FB-5IP). At $0.8 \% \mathrm{drift}$ the influence of numerical localization starts to show up for the SEM, and the previous range increases to an interval between $\phi_{D B}=5.3 \mathrm{~km}^{-1}$ (DPM in OS-DB-PH) and $\phi_{O S-9 I P}=11 \mathrm{~km}^{-1}$ (DPM in OS-FB-9IP). In the post-peak branch, curvatures also localize for the FB formulations at the bottom integration point, while for the SEM they concentrate in the bottom row of elements. It is rather apparent that this numerical feature accentuates as the descending slope of the force-displacement response increases, as shall be seen in detail in the next section. For a drift level of $1.1 \%$, the range of simulated base curvatures varies between $\phi_{D B}=8 \mathrm{~km}^{-1}$ and $\phi_{O S-9 I P}=37.5 \mathrm{~km}^{-1}$, again for the models OS-DB$\mathrm{PH}$ and OS-FB-9IP, respectively. It is noted that the post-peak drift level of $1.1 \%$ for the SEM still corresponds to a pre-peak level for the DB approach (see Fig. 4), which helps explaining why this latter model provides the lower-bound estimates of base curvatures. The previous observations confirm those from the strain plots of Fig. 5, underscoring an inconsistency between distinct simulation techniques for large drift values.

\subsection{Localization and Other Numerical Issues}

The present section starts by defining the limits of response objectivity applicable both to DPMs and SEMs; PHA is not affected by localization issues but is also not suited for capturing the post-peak response (Table 1). Beyond this threshold, the appearance of localization issues entails mesh-dependent results. As pointed out by Bazant [99], this phenomenon is directly related to particular computational problems occurring with materials described by softening constitutive laws. Such descending branch of the stress-strain relation leads to mathematical difficulties as the boundary value problem becomes ill-posed and the response is no longer unique. Initially, localization has been studied for classic finite elements that build on the use of displacement interpolation func- 

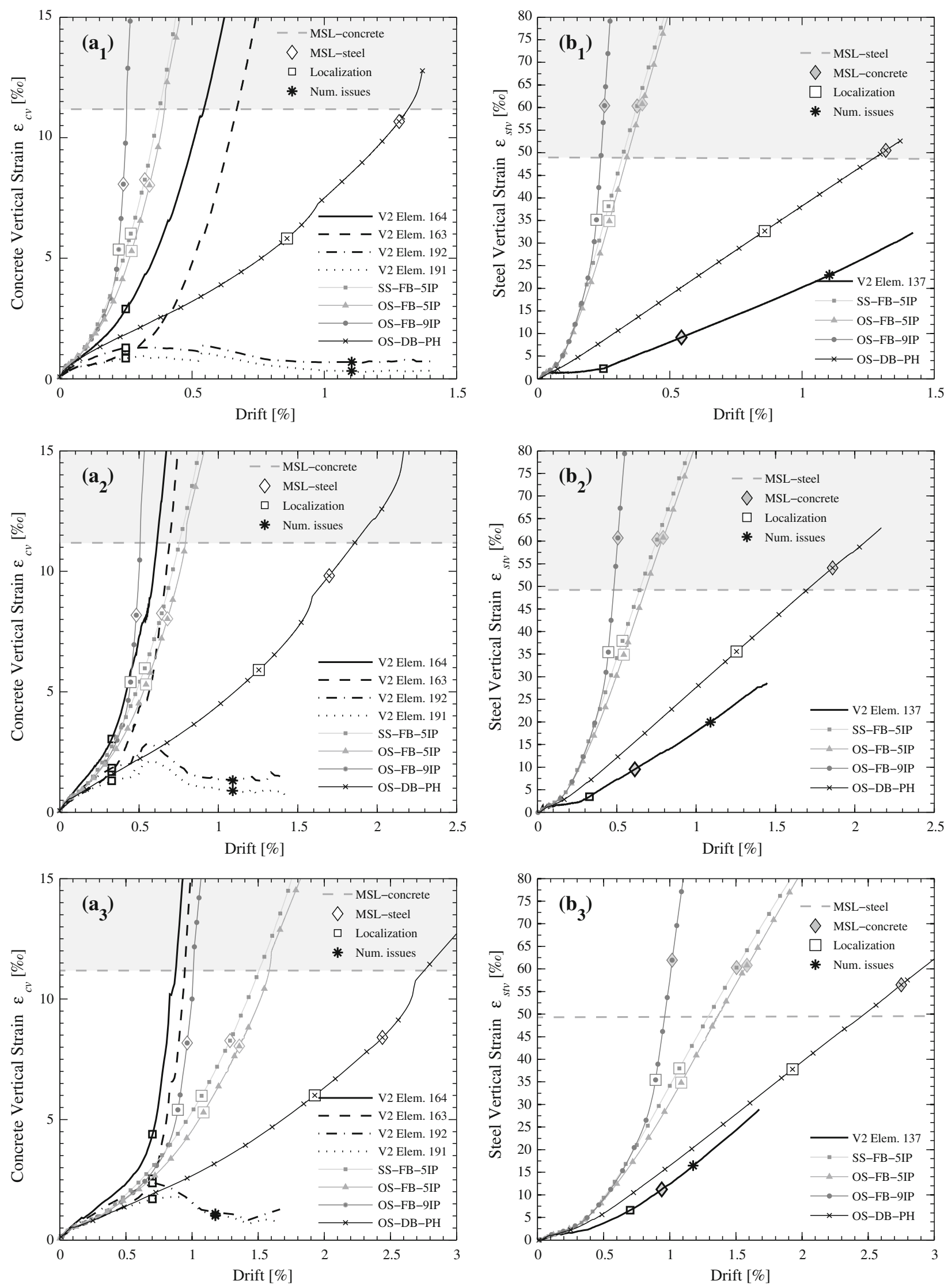

Fig. 5 Local-level concrete and steel strains. $\mathbf{a}_{1}, \mathbf{b}_{1} L_{S} / h \approx 0.78 ; \mathbf{a}_{2}, \mathbf{b}_{2} L_{S} / h \approx 1.56 ; \mathbf{a}_{3}, \mathbf{b}_{3} L_{S} / h \approx 3.1$ 

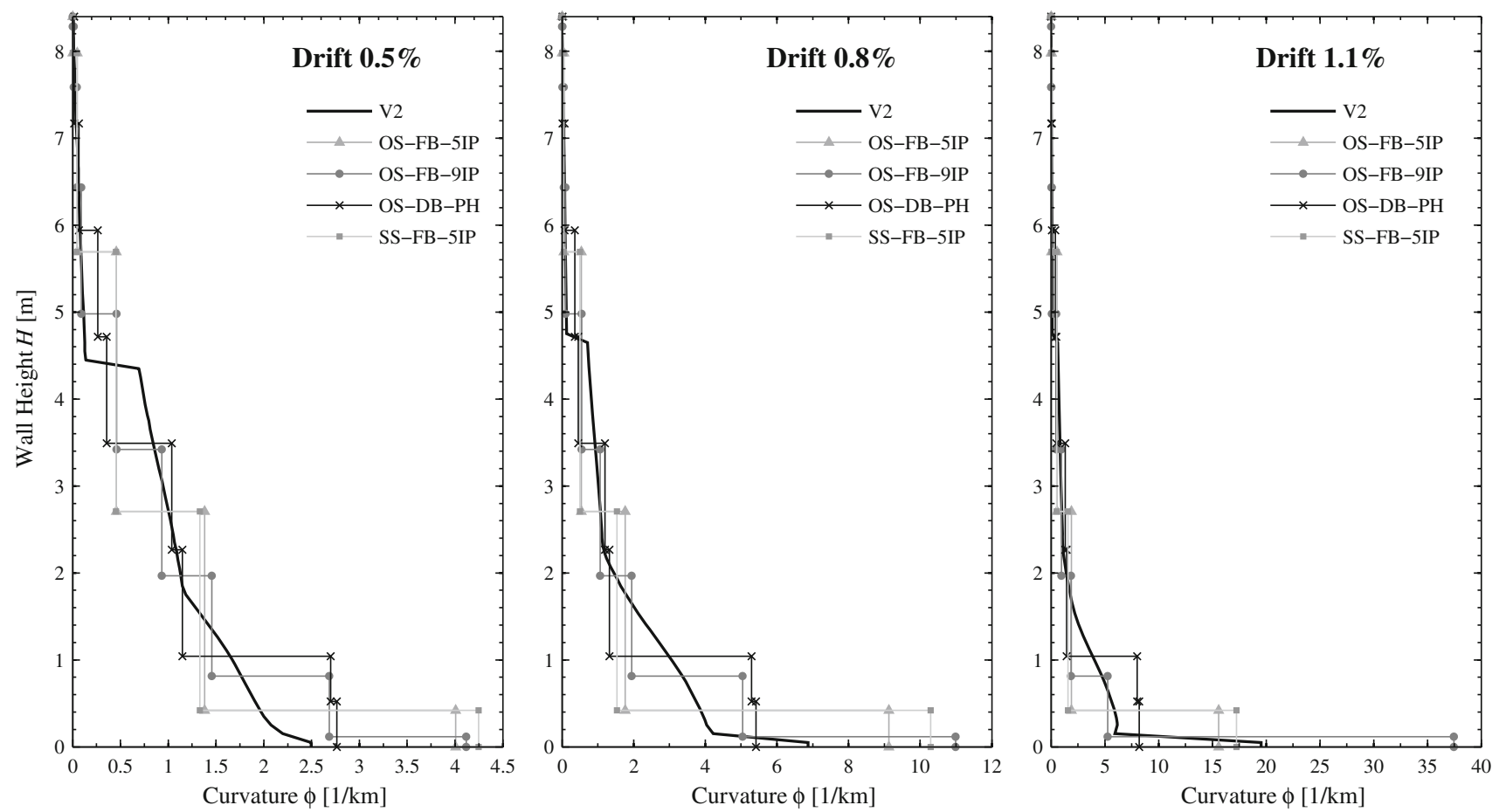

Fig. 6 Curvature profiles along the wall height $\left(\mathrm{L}_{s} / h \approx 3.1\right)$

tions, both for uni-dimensional beam formulations [100] and multi-dimensional SEMs, such as membranes, shells, solids, etc [101]. Following the more recent development of forcebased beam elements, the specific features of localization afflicting this type of approach have also been studied [49]. Hereinafter the occurrence of this issue is shown for all the above-mentioned modelling techniques.

Starting with the DPMs (FB-5IP, FB-9IP, DB), the moment-curvature curves of the sections located in the proximity of the wall base, for the case of $L_{S} / h \approx 3.1$, are displayed in Fig. 7. Each curve shows ten markers indicating equal intervals of drift until a maximum value corresponding to a drop of $10 \%$ of the wall capacity. The flexural capacity of the section for the applied axial load is also reported by a horizontal grey dashed line. As observable in plots $\left(a_{1}\right)$ and $\left(a_{2}\right)$ for FB-5IP, after the peak of the moment-curvature response in the base section (attained for $\phi \approx 12 \mathrm{~km}^{-1}, 6^{\text {th }}$ marker), the deformations start concentrating at the base IP whereas the section above begins to unload. The same behaviour can be noticed for FB-9IP model-plots $\left(b_{1}\right)$ through $\left(b_{3}\right)$ - with the notable difference that the curvature concentration in the base section progresses at a much faster rate: there are roughly four equal drift intervals for the curvature range $\phi \in[12,32] \mathrm{km}^{-1}$ in plot $\left(a_{2}\right)$, whilst an even larger increase in curvature $\phi \in\left[12,36 \mathrm{~km}^{-1}\right.$ is covered by only two equal drift intervals in plot $\left(b_{3}\right)$. This is due to the different integration weights of the base section where the deformations concentrate ( 0.028 for FB-9IP and 0.1 for FB-5IP, out of a total element integration weight of 2).
A very distinct localization pattern occurs for DB formulations, wherein curvatures concentrate simultaneously in both sections of the base element: as shown in plot $\left(c_{1}\right)$, it is the bottom section of the second element above the base that starts unloading. Furthermore it is noticeable that the maximum moments from the sectional results of the base element, plots $\left(c_{2}\right)$ and $\left(c_{3}\right)$, differ from the maximum flexural capacity of the section for the applied axial load. This discrepancy is due to the fact that DB formulations do not strictly verify equilibrium and hence the axial force along the element equals only on average the load applied externally, i.e., the axial force is different for the two IPs. One should be aware, however, that in DB elements it is also possible to have concentration of curvatures in only one IP [57], depending mainly on the axial load ratio, boundary conditions, and element length.

The occurrence of localization in SEM analyses is shown in Fig. 8a for $L_{s} / h \approx 3$.1. It shows the vertical stress-strain curves of the four elements located at the compressed corner of the wall (Fig. 2). The $\sigma_{v}-\varepsilon_{v}$ curves are plotted up to a drift level of $0.8 \%$, which roughly corresponds to the peak of the global force-displacement response. Once again, markers on each curve represent equally spaced drift intervals. The interpretation of the results indicates that above a certain drift level the strains concentrate in the foundationcontiguous elements (no. 163 and 164), while the elements of the row above (no. 191 and 192) start to unload. In this study, the drift level at the onset of localization for SEMs has been identified by the occurrence of the first negative post- 


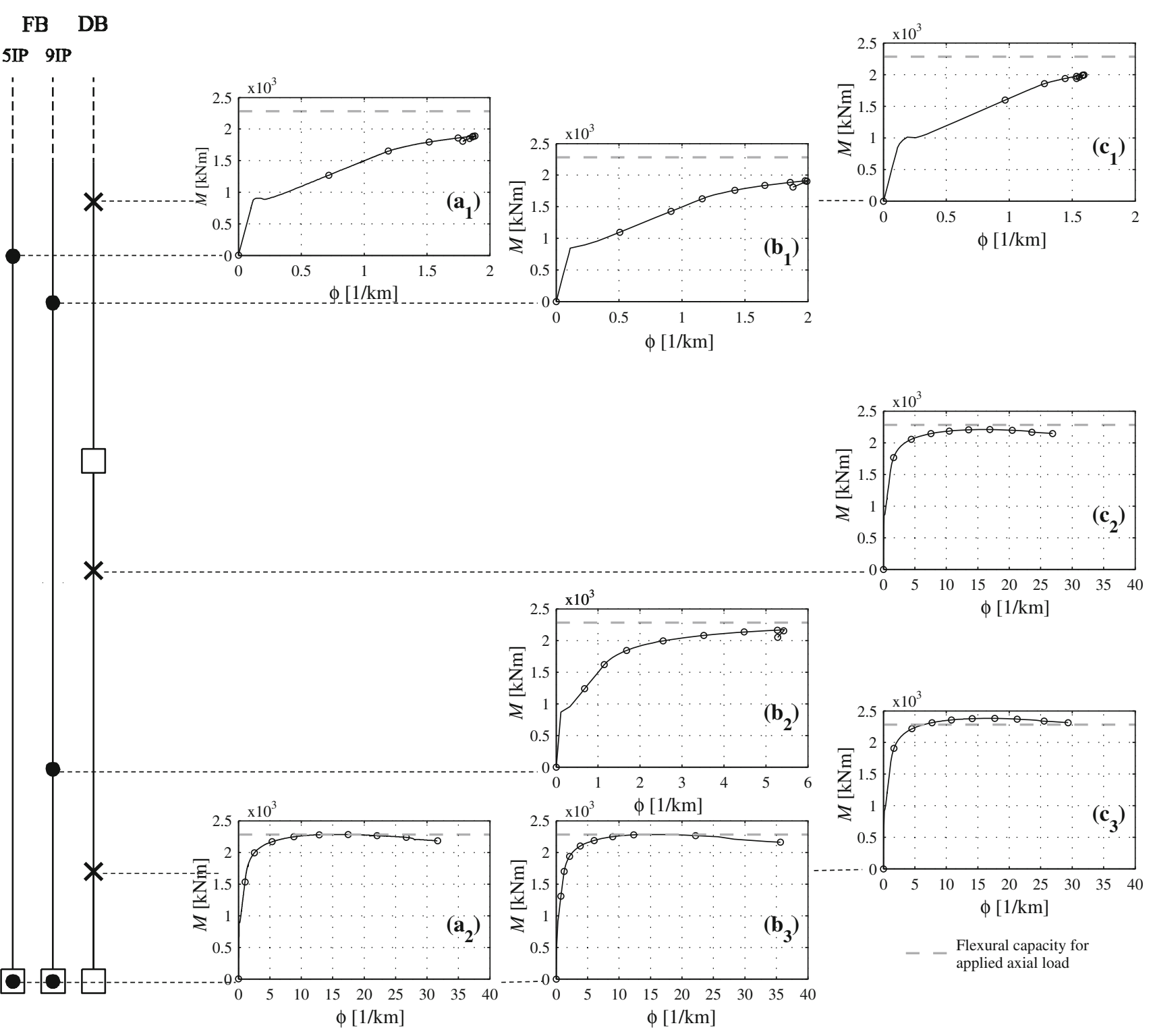

Fig. 7 Numerical localization in DPMs (FB and DB), near the wall base

yield slope of the vertical compressive stress-strain relation, amongst all the elements of the mesh. This was considered as a cautious but reliable indicator of the beginning of meshdependent results. It is however noted that in SEMs the existence of stress and strain gradients (e.g. in walls) typically reduce the relevance of localization on the prediction of the force-displacement response, when compared to members in approximately uniform compression (e.g. concrete cylinders, axially loaded column).

Figure $8 \mathrm{~b}$ shows the same vertical stress-strain curves as Fig. 8a, for elements no. 163 and 164, however this time extended until the end of the analysis (drift level of $1.7 \%$ ). The purpose of these plots is to show the occurrence of a 'waggling' behaviour of the stress-strain curves for strains above approximately $5.5 \%$, which is indicative of unidenti- fied numerical issues. The latter are common (e.g. convergence problems) and to a certain extent inevitable in structural analysis software; however they can often be corrected, alleviated, or even eliminated for specific combinations of input parameters, material or element models, convergence criteria, global solution methods, etc. Such combinations are difficult to define a priori, hence in general the user should be aware of the likely occurrence of numerical issues, which render the computational output untrustworthy; therefore, the authors decided to explicitly include the identification of this phenomenon in the analyses, defining its manifestation under the broad designation of 'numerical issue'. They were pointed out, in particular, in the figures of Sects. 6.3 and 6.4, which comfortingly show that-for the specific member under analysis and the considered software-they 


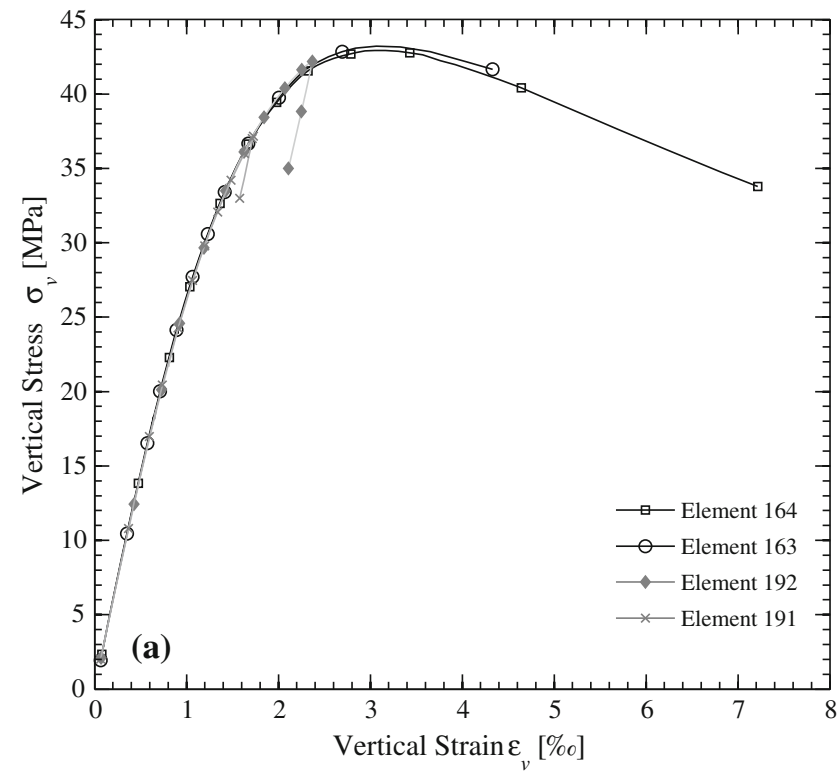

Fig. 8 SEMs: a Numerical localization; b numerical issues

took place for drift levels above the attainment of material strain limits and localization onset. It is highlighted that the local-level irregular behaviour of specific elements (such as the one depicted in Fig. 8(b)) does not necessarily reflect at the global-level response (Fig. 4); the importance of carrying out a multi-level assessment of the structural analysis is therefore, and once again, strongly recommended.

In general, MSLs may be reached before localization occurs, even if this was not the case of the analysed walls: for DPMs, the most strained fibres may be in the post-peak branch of their assigned uniaxial material relation while the moment-curvature curve has not yet reached the softening branch that triggers localization; for SEMs, the inclusion of other phenomena such as explicit modelling of confinement—which is considered in Sect. 6.7-may lead to significantly large values of strain corresponding to compressive strength and therefore facilitate the attainment of a MSL or the avoidance of localization altogether.

Even when localization is the controlling factor (either for DPMs and SEMs), its pernicious effects may not be necessarily very significant and therefore a careful analysis of the steepness of the post-peak branch at local level is advised.

\subsection{Shear Deformation}

The effect of shear deformations, as accounted for in SEMs, is addressed in the following paragraphs. The shear displacements at the effective height of the wall were computed as the difference between the total and the flexural displacements. The latter are determined as the double integration of the curvature profile along the member height. The ratios of shear-to-flexural deformation $\left(\Delta_{s} / \Delta_{f}\right)$ for the dif-
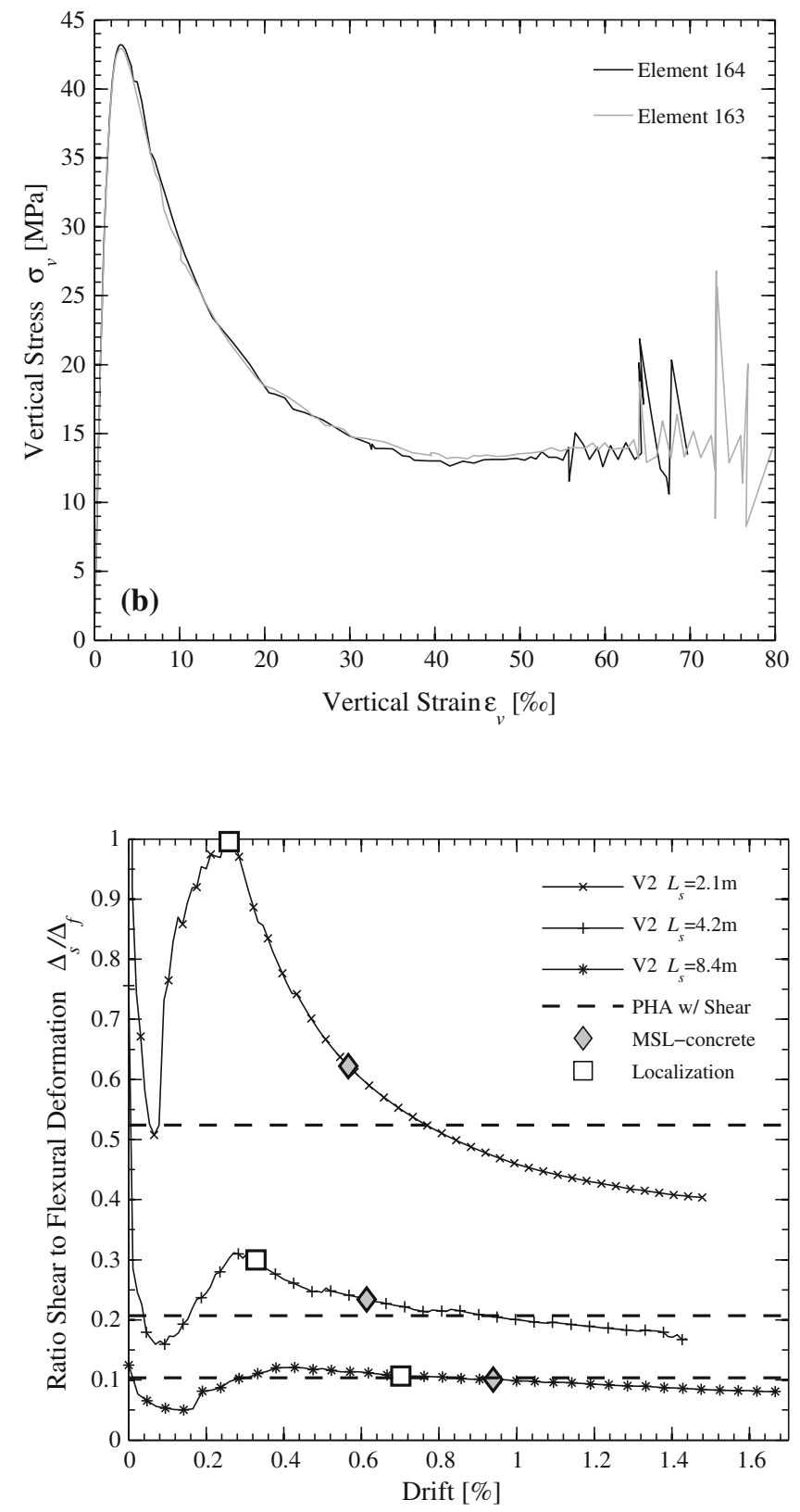

Fig. 9 Ratio of shear-to-flexural deformations for different shear spans

ferent shear span ratios are shown in Fig. 9. As expected, they increase for decreasing shear span ratios and are of the order of $10 \%, 20 \%$ and higher than $50 \%$ respectively for $L_{s} / h \approx 3.1, L_{s} / h \approx 1.56$, and $L_{s} / h \approx 0.78$. These values closely agree with the estimates provided by the PHA model accounting for shear, which are also depicted as dashed horizontal lines in the same figure. Furthermore, with the exception of the least flexure-dominated case, the ratio $\Delta_{s} / \Delta_{f}$ tends to become approximately constant as the member is loaded into its inelastic range. This behaviour had already been experimentally observed by Dazio et al. [61] for RC walls whose shear transfer mechanism is not significantly degrading. 

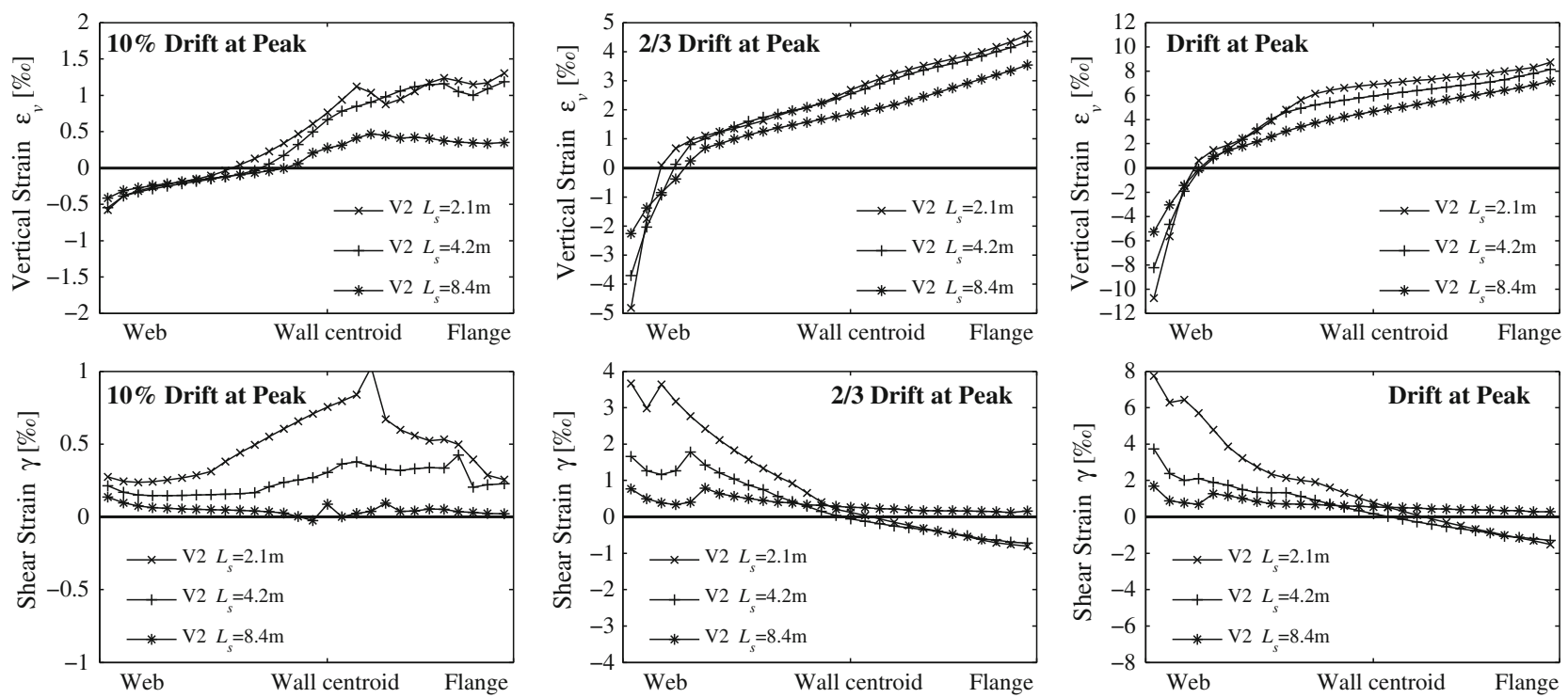

Fig. 10 Vertical and shear strain profiles at the wall base
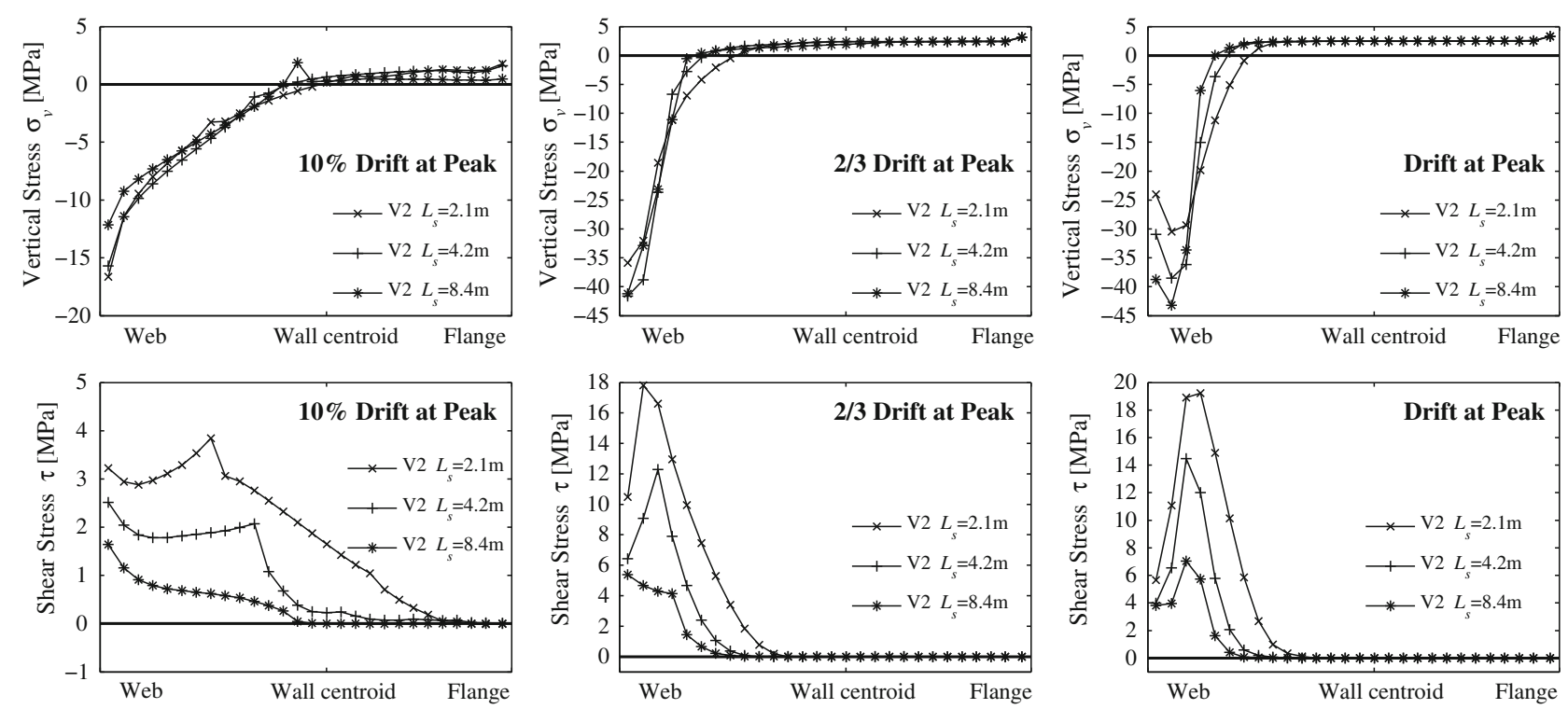

Fig. 11 Vertical and shear stress profiles at the wall base

The vertical and shear strains profiles of the wall base section corresponding to three different drift levels are shown in Fig. 10. They were chosen as representative of: (i) a closeto-elastic phase, (ii) the beginning of the inelastic response, and (iii) the attainment of the wall lateral force capacity (designated as 'drift at peak').

Concerning the vertical strains it is possible to notice how the approximately linear distribution for $10 \%$ of the 'drift at peak' progressively evolves to a nonlinear distribution at larger demands. This remark holds independently of the chosen shear span ratio and points out the limitation of the planesection-remaining-plane hypothesis assumed for DPMs, discussed below in further detail.
The shear strain profiles, besides depending on the considered drift level, seem to be affected by the shear span ratio as well: their absolute value increases with the drift level and decreases with the shear span. Furthermore, it can be observed that, for $L_{s} / h \approx 3.1$, the shear strain distribution remains approximately constant along the entire section of the wall independently of the imposed drift. Such fact suggests that, for elements behaving predominantly in flexure, the constant shear strain hypothesis-as adopted by Timoshenko beam theory-seems to be reasonable. The previous rationale, on the other hand, does not appear valid for smaller shear span ratios (even for nearly elastic response) since the shear strain profile cannot be assimilated to a constant func- 


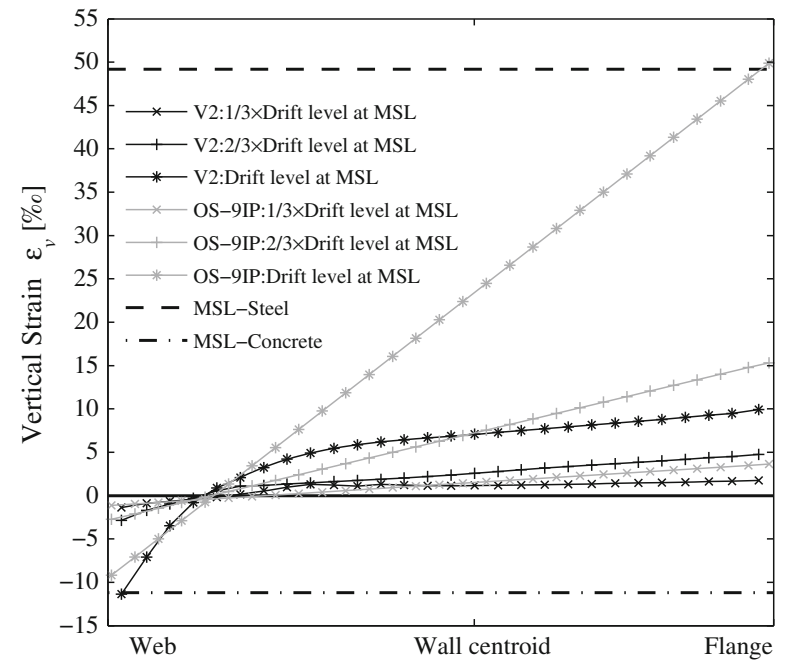

Fig. 12 Comparison of the vertical strain profiles between the SEM and OS-FB-9IP $\left(L_{s}=8.4 \mathrm{~m}\right)$

tion. Eventually, for higher values of drift, shear strains tend to clearly concentrate in the compressed part of the section as a significant amount of the shear stress is transferred to the foundation through the compression zone (Fig. 11).

Finally, Fig. 12 exhibits the comparison between the base section vertical strains from the SEM and DPM OS-FB9IP. The results refer to the most flexure-dominated case $\left(L_{s} / h \approx 3.1\right.$ ) and to levels of drift corresponding to $1 / 3,2 / 3$, and the full attainment of the MSL. The latter, which occurs approximately at the same drift level both for the SEM and the OS-FB-9IP model, is actually misleading since in one case the concrete is governing while in the other the steel MSL is attained.

As it can be seen, for low drift levels the vertical strains predicted by the two models are in acceptable agreement, particularly considering the profile along the section. For larger values of top lateral displacement, the concentration of shear strains and stresses in the compression side greatly impacts the linearity of the vertical strain profiles simulated with VecTor2. It is therefore comprehensible that while the steel MSL is reached for the DPM (which assumes a linear strain profile along the section), the concrete MSL governs the SEM analyses. The importance of carrying out a multi-level assessment again becomes obvious: although the global-level response given by the SEM and DPM shows a very similar behaviour up to the MSL (Fig. 4), the vertical strain profiles and the predicted failure mode are distinct.

\subsection{Influence of confinement models and other physical phenomena}

The confinement effect provided to the concrete core by the transversal reinforcement can be taken into account, during the modelling phase, in different ways. The main approaches used to consider this phenomenon for uniaxial constitutive laws have been briefly described in Sect. 5. Hereafter SEMs using different confinement options are compared at the global and local levels. Other features influencing significantly the outcomes of the analyses are addressed as well.

Strength and ductility enhancement due to confinement is simulated in VecTor2 by a strength enhancement factor, $\beta_{l}$ [52]. It modifies the concrete compression response by increasing both the uniaxial compressive strength $f_{c}^{\prime}$ and the corresponding strain $\varepsilon_{c}$, as follows:

$f_{p}=\beta_{l} f_{c}^{\prime} \quad \varepsilon_{p}=\beta_{l} \varepsilon_{c}$

Different models are available to calculate $\beta_{l}$. However, in the present section only the program default and recommended option is considered: it consists of a combination of the relationship proposed by Kupfer et al. [102] with the one proposed by Richart et al. [81]. Additionally, it is the simplest to interpret and hence it is deemed the most suitable for engineering practice. The other available confinement models require the solution of the material failure surface [103,104], which is more complex and computationally demanding.

Besides the strength enhancement due to confinement, several other material effects can in general be taken into account in shell element models. Amongst them, models addressing features such as compression softening, tension stiffening, tension softening, tension splitting, concrete expansion, reinforcement dowel action, and reinforcement buckling are available. For the specific structure in analysis, tension stiffening and tension softening turned out to impact the results the most until the peak. The former accounts for the average tensile concrete stresses after concrete cracking due to the bond action with the reinforcement, whilst the latter addresses the presence of post cracking tensile stresses in plain concrete entailed by the fact that the material is not perfectly brittle. Both features result in a redistribution of the concrete stresses upon cracking, which otherwise would abruptly reduce to zero causing a discontinuous change in the structural stiffness.

Table 5 lists the four models compared in this section as well as the material effects that were accounted for to distinguish them. The remaining properties of the constitutive materials that are not depicted in the table are the same as those used in the previous sections (recall, namely, the description in Sect. 6.2); only the following adjustment was made: in the models where concrete strength enhancement is directly addressed by the use of a confinement model ( $M 1$ and $M 3$ in the table below), nominal values for the cylinder strength and peak strain are given as input $\left(f_{c}^{\prime}=37 \mathrm{MPa}, \varepsilon_{c}=2 \%{ }_{0}\right)$. It is recalled that for the models labelled as Basic and $M 2$, the confinement effect is also accounted for by a direct input of the enhanced material prop- 
Table 5 Models for the evaluation of confinement effect and other physical phenomena

\begin{tabular}{llllll}
\hline Model & Confinement & Tension stiffening & Tension softening & Compression softening & Dilation \\
\hline Basic & N.C.E.* & N.C.** & N.C.** & N.C.**ack slip \\
M1 & Kupfer-Richart & N.C.** & N.C.** & N.C.** & Constant $v^{* * *}$ \\
M2 & N.C.E.* & Modified Benz & Linear & N.C.**** & Constant $v^{* * *}$ \\
M3 & Kupfer-Richart & Modified Benz & Linear & Vecchio 1992A & Constant $v^{* * *}$ \\
\hline
\end{tabular}

* Not considered explicitly; ** Not considered; *** Poisson ratio
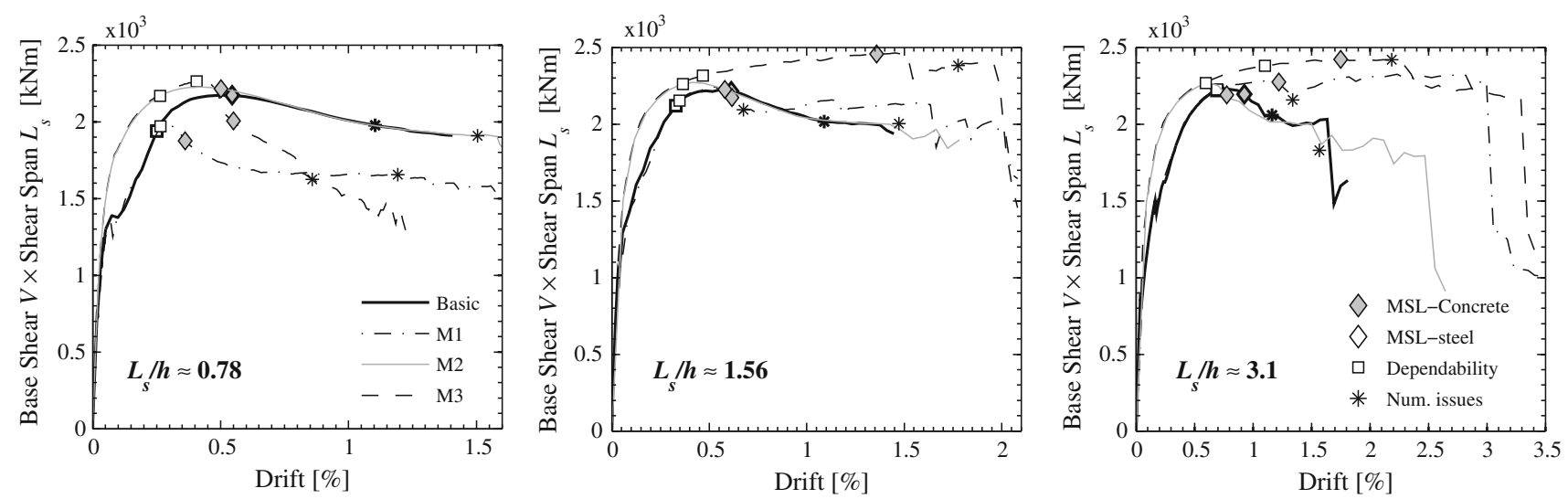

Fig. 13 Confinement and other physical phenomena: global-level comparison

erties according to Mander's model [53], and therefore a unitary strength enhancement factor $\left(\beta_{l}=1\right)$ is assumed.

The Basic model is the one employed in all the analyses so far. $M 1$ differs solely by the use of the Kupfer-Richart confinement model. $M 2$ takes into account the tension stiffening and tension softening effects, as discussed above. Eventually, M3 considers all the concrete physical phenomena available in VecTor2 default options, the most relevant of which are indicated in Table 5.

The base shear for the three wall heights are plotted in Fig. 13 times the corresponding shear span in order to make the results comparable. A first immediate conclusion from the comparison between the models Basic and $M 1$ is that different techniques of confinement simulation can affect substantially the predicted global response of the structural member. It is possible to argue that the results given by the $M 1$ model are in principle more realistic. In fact, as discussed above, the concrete stress-strain relations along the principal directions of the Basic model are insensitive to the multi-dimensional strain and stress states to which they are subjected; all the plane stress rectangles, independently of the shear span ratio and the respective position in the mesh, follow an identical constitutive law, fixed a priori. In the $M 1$ model, on the other hand, the strength enhancement factor is computed for each element according to the assigned confinement model. The value of $\beta_{l}$ is thus a function of the varying triaxial stress state at the local level, increasing with the lateral confining stress acting on the concrete.
For the present case study, the dependence of the results on the stress flow within the structure is evident. For $L_{S} / h \approx$ 0.78 , the increased importance of the shear deformation mechanism induces a shear stress state in the mesh elements that prevents strength enhancement, i.e. $\beta_{l}=1$ according to the Kupfer/Richard relation defined in VecTor2 [52]. As a more flexural type of deformation mechanism takes place and the shear stresses lose relative weight, as it is the case for $L_{S} / h \approx 1.56$ and $L_{S} / h \approx 3.1$, the inclination of the compression strut becomes more vertical and enables the formation of a well confined zone at the compressed side of the wall base. This produces relatively large enhancement factors, of the order of $\beta_{l}=1.15$ for $L_{s} / h \approx 3.1$, that lead to an increase of the wall force and displacement capacities.

Concerning the effect of tension stiffening and tension softening, a comparison should be made between the Basic and M2 models. It is apparent that these features mainly impact the ascending branch of the force-displacement curves; in between the occurrence of cracking and the attainment of the wall force capacity, the member shows a relative increase in strength due to the presence of post-cracking concrete tensile stresses. As a beneficial numerical side effect, no sudden changes of structural stiffness can be observed up to peak, after which both models tend to provide an identical response prediction.

The results of M3 allow a few additional observations. Firstly, since the results are identical to those of $M 2$ up 

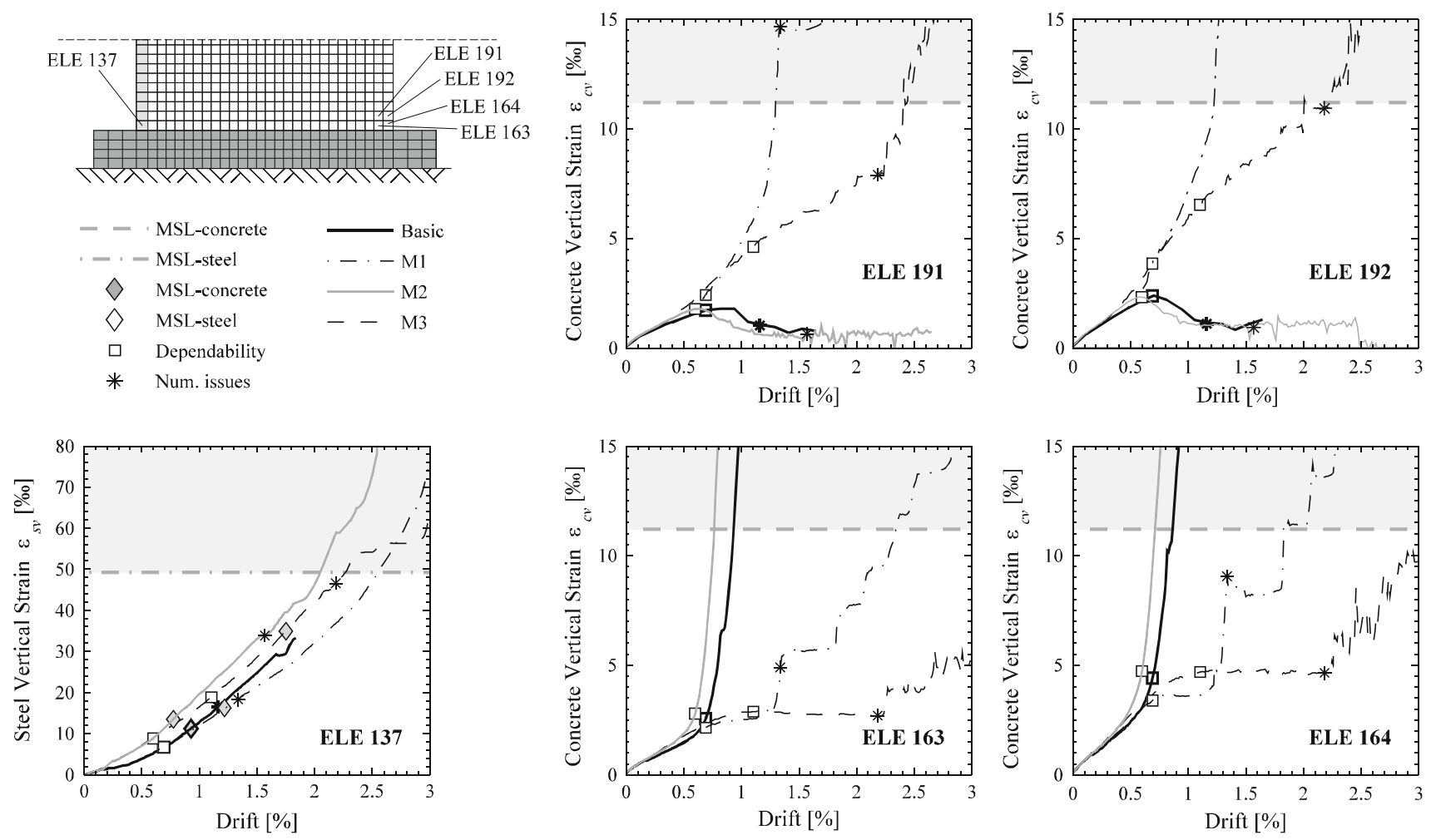

Fig. 14 Confinement and other physical phenomena: local-level comparison

to peak (for all the shear spans), this confirms that tension stiffening and softening are the modelling options that mainly affect the ascending branch of the force-displacement response. Secondly, it shows that the other unaddressed physical phenomena (such as variable lateral expansion, compression softening, crack slip, etc) have a relevant influence on the response; they seem to interplay with the previously described physical effects, as well as with the different strain and stress states imposed by the distinct shear span ratios, in a way that cannot be straightforwardly understood from the present set of analyses. An additional sensitivity study would be required to untangle the problem intricacy. Along the same line, as a last overall remark, it is noted that the complexity of the model behaviour significantly increases after the indicated dependability limits.

As discussed in several occasions above, a structural analysis is not deemed complete until a multi-level assessment has been performed. Therefore, Fig. 14 presents a locallevel comparison of the same models for the most flexuredominated case $\left(L_{S} / h \approx 3.1\right)$; in particular, it depicts the concrete vertical strains of the four elements in the compressed side of the wall, as well as the steel vertical strains in the tensile wall edge.

The evolution of the concrete vertical strains is quite similar for models Basic and M2. In both cases, following the onset of localization, strains concentrate in the bottom row elements (no. 163 and 164) while the elements above (no.
191 and 192) begin unloading. Such observation expresses the insensitivity of the model to the effects of tension stiffening and tension softening after the peak, as expected from the global-level results, see Fig. 13. On the other hand, the effect of explicitly considering a confinement model (in $M 1$ and $M 3$ ) seems to play a major role in the features of SEM localization: it now occurs simultaneously in the four elements (no. 163, 164, 191, and 192), while the unloading takes place outside the selected region. Regarding the simulation of the tensile steel strains, Fig. 14 presents evidence of a good agreement between the different models. ${ }^{2}$

\section{Conclusions}

Specialized earthquake engineering practice currently resorts to a variety of modelling techniques to simulate the inelastic behaviour of RC walls. They broadly range from simple and fast plastic hinge analyses (PHAs) based on bilinear idealizations of the moment-curvature curve, to timeconsuming shell element models (SEMs) that make use of advanced multi-dimensional concrete and steel constitutive models. At intermediate levels of computational speed and output detail, one can find a wealth of approaches, typically

2 Due to numerical issues, the Basic model does not reach the steel MSL. 
developed within the framework of beam theory; amongst them, the so-called distributed plasticity models (DPMs) are arguably the most well-known. Each of the abovementioned approaches is composed of different levels of analysis, which in the current document were categorized into local (material and sectional, if applicable) and global levels (element and structure).

All the above techniques-mainly PHAs and DPMsare widely employed in performance-based assessment and design of structures. The latter builds primarily on the accuracy of global-level force-displacement response curves. However, some recent codes and guidelines are encouraging structural assessment based on local-level output quantities, like concrete and rebar strains, as they relate directly to structural damage. The main goal of this study was to evaluate the scatter of these local-level simulations, compare it with the scatter obtained at the global level, explore the numerical and theoretical reasons for potential discrepancies, and formulate recommendations for the analysis of RC walls. A cantilever wall with three distinct but realistic shear span ratios, subjected to simple pushover loadings, served as case study. The input model parameters of the different modelling approaches were chosen in such a way as to minimize the inevitable inconsistencies arising from different software options.

Starting from the results of the more slender wall where a predominantly flexural response is expected, the present study showed that the employed modelling techniques provide a scatter of predictions that increases very significantly from the global to the local level. Simulation of global quantities such as stiffness evolution up to peak or force capacity do not seem to be sensitive to the chosen modelling approach, which can therefore convey a deceitful impression of consistency between the different numerical tools. However, this misleading agreement was shown not to hold for what regards the prediction of local-level engineering demand parameters (concrete and rebar strains). While during an early phase of the response, roughly until the peak of the force-displacement curve, such divergences are somewhat limited, even if nonnegligible, they become extremely significant after the occurrence of localization. This fact indicates that performancebased assessment of RC walls relying on non-regularized strain EDPs can in general be highly untrustworthy and hence it is not yet recommended for current engineering practice. The consideration of other unmodelled phenomena, such as strain penetration or anchorage failure, would further reinforce this conclusion.

The importance of carrying out an extensive multi-level assessment of each output is the second conclusion of this study. This appears fundamental to characterize the dependability of the response and, hence, to evaluate the ultimate displacement. To estimate the range of results wherein the results can be considered dependable, it was shown that three distinct issues should be taken into account. First off, one should make sure that pre-defined strain limits for the material constitutive relations, below which the models are judged physically representative, are not exceeded. Secondly, possible unwarranted consequences of numerical localization, which were shown to manifest in very different forms for each modelling approach, have to be identified. Lastly, the occurrence of other numerical issues that can potentially impact the reliability of the results should also be monitored. For the case studies in the present paper, localization was shown to be the conditioning factor. Such observation suggests the need to concentrate research and software development efforts in the application of consistent regularization techniques in order to push the reliability threshold towards higher levels of displacement demands. Although there are regularization methods available for beam and shell element models, they are still not widely spread in engineering software. Perhaps more importantly, future improvements in the prediction of local EDPs should be based on deeper understanding and characterization of damage localization in experimentally tested wall specimens, in order to calibrate the numerical regularization techniques.

Software limitation often constrains engineers to use DPMs and classical PHAs even when the influence of member shear deformations is expected to be non-negligible. The two walls with the shorter span ratios were used to evaluate the additional modelling error due to the non-consideration of shear, in comparison with the shell model. Although there was an unsurprising increase in the disagreement between the simulation methods both at the global and local levels, it was again particularly evident at the latter, which underlines the care that should be put when using strains as engineering demand parameters.

Acknowledgments The work was financially supported by the Stiftung zur Förderung der Denkmalpflege in the framework of the project 'Erbebenverhalten von bestehenden Stahlbetongebäuden mit dünnen Wänden'. The authors would like to thank the invaluable support provided by Prof. Frank Vecchio, from the University of Toronto, regarding the use of software VecTor2. The suggestions given by Prof. Rui Pinho, who thoroughly reviewed the manuscript, and by Prof. Sri Sritharan, are also kindly acknowledged. Finally, a word of gratitude goes to Hugues Vincent for the work carried out during his internship at the Earthquake Engineering and Structural Dynamics Laboratory, in École Polytechnique Fédérale de Lausanne.

\section{References}

1. SEAOC (1959) Recommended lateral force requirements and commentary. Seismology Committee, Structural Engineers Association of California, First Edition

2. Bozorgnia Y, Bertero VV (2004) Earthquake engineering-from engineering seismology to performance-based engineering. CRC Press

3. SEAOC (1980) Recommended lateral force requirements and commentary. Seismology Committee, Structural Engineers Association of California, Fourth Edition Revised 
4. ATC-3-06 (1978) Tentative provisions for the development of seismic regulations for buildings. Applied Technology Council, California

5. EN1998-3 (2005) Eurocode 8: design of structures for earthquake resistance. Part 3: Assessment and retrofitting of buildings. Doc CEN/TC250/SC8/N306

6. FEMA 356 (2000) Prestandard and commentary for the seismic rehabilitation of buildings. Federal Emergency Management Agency. California, USA

7. ATC-40 (1996) Seismic evaluation and retrofit of concrete buildings. Applied Technology Council. Redwood City, CA

8. SEAOC (1995) Vision 2000—-performance based seismic engineering of buildings. Structural Engineers Association of California. Sacramento, California, USA

9. ASCE (2006) ASCE/SEI 41-06: seismic rehabilitation of existing buildings. ASCE, Reston

10. FEMA (2012) FEMA P-58-1: seismic performance assessment of buildings, vol. 1-Methodology. Prepared by the Applied Technology Council for the Federal Emergency Management Agency. USA

11. FEMA (2012) FEMA P-58-2: seismic performance assessment of buildings, vol. 2-Implementation guide. Prepared by the Applied Technology Council for the Federal Emergency Management Agency. USA

12. EN1998-1 (2004) Eurocode 8: design of structures for earthquake resistance. Part 1: general rules, seismic actions and rules for buildings. Doc CEN/TC250/SC8/N306

13. FEMA 368 (2001) NEHRP recommended provisions for seismic regulations for new buildings and other structures. Federal Emergency Management Agency. Washington D.C., USA

14. ASCE 7-02 (2002) Minimum design loads for buildings and other structures. American Society of Civil Engineers. Reston, VA, USA

15. Romão X, Delgado R, Costa A (2010) Practical aspects of demand and capacity evaluation of RC members in the context of EC8-3. Earthq Eng Struct Dyn 39:473-499

16. Whittaker A, Deierlein GG, Hooper J, Merovich A (2004) ATC58 project task report: engineering demand parameters for structural framing systems. Prepared for the Applied Technology Council by the ATC-58 Structural Performance Products Team. USA

17. Computers and Structures Inc. (2013) Perform-3D: nonlinear analysis and performance assessment for 3D structures. Computers and Structures Inc., Berkeley

18. Computers and Structures Inc. (2013) ETABS 2013: integrated analysis, design and drafting of building systems. Computers and Structures Inc., Berkeley

19. SeismoSoft (2013) SeismoStruct—a computer program for static and dynamic nonlinear analysis of framed structures

20. OpenSees (2013) Open system for earthquake engineering simulation, version 2.4.3

21. Wong PS, Vecchio FJ, Trommels H (2014) VecTor2—software for nonlinear analysis of two-dimensional reinforced concrete membrane structures

22. Berry MP, Lehman DE, Lowes LN (2008) Lumped-plasticity models for performance simulation of bridge columns. ACI Struct J 105(3):270-279

23. Mackie K, Stojadinovic B (2001) Seismic demands for performance-based design of bridges. In: PEER annual meeting

24. Sritharan S, Beyer K, Henry RS, Chai YH, Kowalsky M, Bull D (2014) Understanding poor seismic performance of concrete walls and design implications. Earthq Spectra 30(1): 307-334

25. Ile N, Reynouard JM (2005) Behaviour of U-shaped walls subjected to uniaxial and biaxial cyclic lateral loading. J Earthq Eng 9(1):67-94
26. Mazars J, Kotronis P, Ragueneau F, Casaux G (2006) Using multifiber beams to account for shear and torsion. Comput Methods Appl Mech Eng 195(52):7264-7281

27. Sittipunt C, Wood SL (1993) Finite element analysis of reinforced concrete shear walls. Report, University of Illinois, Urbana, Illinois

28. Palermo D, Vecchio FJ (2007) Simulation of cyclically loaded concrete structures based on the finite-element method. J Struct Eng 133(5):728-738

29. Beyer K, Simonini S, Constantin R, Rutenberg A (2014) Seismic shear distribution among interconnected cantilever walls of different lengths. Earthq Eng Struct Dyn 43(10):1423-1441

30. Orakcal K, Massone LM, Wallace JW (2006) Analytical modeling of reinforced concrete walls for predicting flexural and coupled shear-flexural responses. Report No. PEER 2006/07, PEER University of California at Berkeley, Los Angeles, California

31. Beyer K, Dazio A, Priestley MJN (2008) Seismic design of torsionally eccentric buildings with U-shaped RC walls, Pavia. Research Report ROSE School, Pavia

32. Beyer K, Dazio A, Priestley MJN (2008) Inelastic wide-column models for U-shaped reinforced concrete walls. J Earthq Eng 12(sup1): $1-33$

33. Miki T, Niwa J (2004) Nonlinear analysis of RC structural members using 3D lattice model. J Adv Concr Technol 2(3):343-358

34. Lu Y, Panagiotou M (2014) Three-dimensional cyclic beamtruss model for nonplanar reinforced concrete walls. J Struct Eng 140(3):1-11

35. Lu Y, Panagiotou M (2012) Three-dimensional nonlinear cyclic beam-truss model for non-planar reinforced concrete walls. Report No. UCB/SEMM-2012/01, Department of Civil and Environmental Engineering, University of California at Berkeley, Berkeley, USA

36. Belletti B, Damoni C, Gasperi A (2013) Modeling approaches suitable for pushover analyses of RC structural wall buildings. Eng Struct 57:327-338

37. Yazgan U, Dazio A (2011) Simulating maximum and residual displacements of RC structures: I Accuracy. Earthq Spectra 27(4):1187-1202

38. Hines EM (2002) Seismic performance of hollow rectangular reinforced concrete bridge piers with confined corner elements. Ph.D. Thesis, University of California

39. Paulay T, Priestley MJN (1992) Seismic design of reinforced concrete and masonry buildings. Wiley, New York

40. Priestley MJN, Calvi GM, Kowalsky MJ (2007) Displacementbased seismic design of structures. IUSS Press, Pavia

41. Arbulu AGB (2006) Plastic hinge length in high-rise concrete shear walls. M.Sc. University of British Columbia, Vancouver, Canada

42. Fardis MN (2009) Seismic design, assessment and retrofitting of concrete buildings. Springer, Dordrecht

43. Pam HJ, Ho JCM (2009) Length of critical region for confinement steel in limited ductility high-strength reinforced concrete columns. Eng Struct 31(12):2896-2908

44. Bae S, Bayrak O (2008) Plastic hinge length of reinforced concrete columns. ACI Struct J 105(3):290-300

45. Almeida JP, Das S, Pinho R (2012) Adaptive force-based frame element for regularized softening response. Comput Struct 102 103:1-13

46. NZS 3101 (2006). Concrete structures standard. Part 1 - The design of concrete structures. Standards Council. New Zealand

47. NZS 3101 (2006). Concrete structures standard. Part 2 - Commentary on the design of concrete structures. Standards Council. New Zealand

48. ACI 318 (2002) Building code requirements for structural concrete (ACI 318-02) and Commentary (ACI 318R-02). American Concrete Institute (ACI) Committee. USA 
49. Coleman J, Spacone E (2001) Localization issues in force-based frame elements. J Struct Eng 127(11):1257-1265

50. Scott MH, Fenves GL (2006) Plastic hinge integration methods for force-based beam-column elements. J Struct Eng 132(2):244252

51. Crisfield MA (1990) A consistent co-rotational formulation for non-linear, three-dimensional, beam-elements. Comput Methods Appl Mech Eng 81(2):131-150

52. Wong PS, Vecchio FJ, Trommels H (2013) VecTor2 \& FormWorks User's Manual. University of Toronto

53. Mander JB, Priestley MJN, Park R (1988) Theoretical stressstrain model for confined concrete. J Struct Eng 114(8):18041826

54. Biskinis D, Fardis MN (2010) Flexure-controlled ultimate deformations of members with continuous or lap-spliced bars. Struct Concr 11:93-108

55. Kowalsky MJ (2000) Deformation limit states for circular reinforced concrete bridge columns. J Struct Eng 126(8):869-878

56. Kazaz Í, Gulkan P, Yakut A (2012) Deformation limits for structural walls with confined boundaries. Earthq Spectra 28(3):10191046

57. Calabrese A, Almeida JP, Pinho R (2010) Numerical issues in distributed inelasticity modeling of RC frame elements for seismic analysis. J Earthq Eng 14(S1):38-68

58. Pugh JS, Lowes LN, Lehman DE (2014) Seismic design of concrete walled buildings. In: Second European conference on earthquake engineering and seismology. Istanbul

59. Beyer K, Dazio A, Priestley MJN (2011) Shear deformations of slender reinforced concrete walls under seismic loading. ACI Struct J 108(2):167-177

60. Lodhi MS, Sezen H (2012) Estimation of monotonic behavior of reinforced concrete columns considering shear-flexure-axial load interaction. Earthq Eng Struct Dyn 41:2159-2175

61. Dazio A, Beyer K, Bachmann H (2009) Quasi-static cyclic tests and plastic hinge analysis of RC structural walls. Eng Struct 31(7):1556-1571

62. Hines EM, Restrepo JI, Seible F (2004) Force-displacement characterization of well-confined bridge piers. ACI Struct J 101(4):537-548

63. Miranda PA, Calvi GM, Pinho R, Priestley MJN (2005) Displacement-based assessment of RC columns with limited shear resistance. IUSS Press, Pavia

64. Park R, Paulay T (1975) Reinforced concrete structures. Wiley, New York

65. Xu S, Zhang J (2011) Hysteretic shear-flexure interaction model of reinforced concrete columns for seismic response assessment of bridges. Earthq Eng Struct Dyn 40:315-337

66. Zhang J, Xu S, Tang Y (2011) Inelastic displacement demand of bridge columns considering shear-flexure interaction. Earthq Eng Struct Dyn 40:731-748

67. Guedes J, Pinto AV (1997) A numerical model for shear dominated bridge piers. In: 2nd Italy-Japan workshop on seismic design and retrofit of bridges. Tsukuba, Japan

68. Navarro Gregori J, Miguel Sosa P, Fernández Prada Ma, Filippou FC (2007) A 3D numerical model for reinforced and prestressed concrete elements subjected to combined axial, bending, shear and torsion loading. Eng Struct 29(12):3404-3419

69. Ceresa P, Petrini L, Pinho R, Sousa R (2009) A fibre flexure-shear model for seismic analysis of RC-framed structures. Earthq Eng Struct Dyn 38:565-586

70. Petrangeli M (1996) Modelli numerici per strutture monodimensionali in cemento armato. $\mathrm{PhD}$ Thesis

71. Remino M (2004) Shear modeling of RC concrete structures. Starrylink Editrice Collana Tesi e Ricerca. PhD Thesis
72. Marini A, Spacone E (2007) Analysis of reinforced concrete elements including shear effects. ACI Struct J 103(5):645-655

73. Petrangeli M, Pinto PE, Ciampi V (1999) Fiber element for cyclic bending and shear of RC structures. I: Theory. J Eng Mech 125(9):994-1001

74. Martinelli L (2002) Numerical simulation of cyclic tests of R/C shear walls. In: 12th European conference on earthquake engineering. London, United Kingdom

75. Ranzo G, Petrangeli M (1998) A fibre finite beam element with section shear modelling for seismic analysis of RC structures. J Earthq Eng 2(3):443-473

76. Mergos PE, Beyer K (2013) Modelling shear-flexure interaction in equivalent frame models of slender reinforced concrete walls. Struct Des Tall Spec Build Published Online First. doi:10.1002/ tal

77. Correia AA, Almeida JP, Pinho R (2014) Force-based higherorder beam element with flexural-shear-torsional interaction in 3D frames. Part I: Theory. Eng Struct (accepted for publication)

78. Almeida JP, Correia AA, Pinho R (2014) Force-based higherorder beam element with flexural-shear-torsional interaction in 3D frames. Part II: Applications. Eng Struct (accepted for publication)

79. Vecchio FJ, Collins MP (1986) The modified compression-field theory for reinforced concrete elements subjected to shear. ACI J 83(2):219-231

80. Vecchio FJ (2000) Disturbed stress field model for reinforced concrete: formulation. J Struct Eng 126(9):1070-1489

81. Richart FE, Brandtzaeg A, Brown RL (1928) A study of the failure of concrete under combined compressive stresses. Univ Illinois Bull XXVI(12)

82. Imran I, Pantazopoulou SJ (1996) Experimental study of plain concrete under triaxial stress. ACI Struct J 93(6):589-601

83. Samani AK, Attard MM (2012) A stress-strain model for uniaxial and confined concrete under compression. Eng Struct 41:335-349

84. Cusson D, Paultre P (1995) Stress-strain model for confined highstrength concrete. J Struct Eng 121(3):468-477

85. Willam KJ, Warnke EP (1974) Constitutive model for the triaxial behaviour of concrete. In: Seminar on "Concrete Structures Subjected fo Triaxial Stresses". Bergamo, Italy

86. Cusson D, Paultre P (1994) High-strength concrete columns confined by rectangular ties. J Struct Eng 120(3):783-804

87. Légeron F, Paultre P (2003) Uniaxial confinement model for normal- and high-strength concrete columns. J Struct Eng 129(2):241-252

88. Sheikh SA, Uzumeri SM (1982) Analytical model for concrete confinement in tied columns. J Struct Div 108(ST12):2703-2722

89. Tarquini D (2014) Modelling approaches for inelastic behaviour of RC walls: multi-level assessment and dependability of results. M.Sc. Thesis, ROSE Master Program, Istituto Universitario di Studi Superiori, Pavia, Italy

90. Priestley MJN, Seible F, Calvi GM (1996) Seismic design and retrofit of bridges. Wiley, New York

91. Lin C-S, Scordelis AC (1975) Nonlinear analysis of RC shells of general form. J Struct Div 101(3):523-538

92. Popovics S (1973) A numerical approach to the complete stressstrain curve of concrete. Cem Concr Res 3(5):583-599

93. Hagsten LG, Hestbech L, Fisker J (2011) Energiprincipper-del 3: Betonkonstruktioner. Teori, lecture notes

94. Hannewald P (2013) Seismic behavior of poorly detailed RC bridge piers. Ph.D. Thesis, Thesis No. 5894:183, École polytechnique fédérale de Lausanne, Lausanne, Switzerland

95. Neuenhofer A, Filippou FC (1997) Evaluation of nonlinear frame finite-element models. J Struct Eng 123(7):958-966 
96. Menegotto M, Pinto PE (1973) Method of analysis for cyclically loaded RC plane frames including changes in geometry and non-elastic behaviour of elements under combined normal force and bending. In: IABSE Symposium on resistance and ultimate deformability of structures acted on by well defined repeated loads-Final Report

97. Filippou FC, Popov EP, Bertero VV (1983) Effects of bond deterioration on hysteretic behavior of reinforced concrete joints. University of California, Berkeley

98. De Veubeke BF (1965) Displacement and equilibrium models in the finite element method. In: Stress analysis. Wiley, New York, pp 145-197

99. Bazant ZP (1976) Instability, ductility and size effect in strainsoftening concrete. J Eng Mech Div 102(2):331-344
100. Bazant ZP, Pan J, Pijaudier-Cabot G (1987) Softening in reinforced concrete beams and frames. J Struct Eng 113(12):23332347

101. De Borst R, Sluys LJ, Muhlhaus H-B, Pamin J (1993) Fundamental issues in finite element analyses of localization of deformation. Eng Comput 10(2):99-121

102. Kupfer H, Hilsdorf HK, Rusch H (1969) Behavior of concrete under biaxial stresses. ACI J 66(8):656-666

103. Hsieh SS, Ting EC, Chen W-F (1979) An elastic-fracture model for concrete. In: 3rd ASCE/EMD Specialty Conference, Austin, Texas, pp 437-440

104. Ottosen NS (1977) A failure criterion for concrete. ASCE J Eng Mech Div 103(4):527-535 